Review Article

\title{
Dabigatran, Rivaroxaban, or Apixaban versus Warfarin in Patients with Nonvalvular Atrial Fibrillation: A Systematic Review and Meta-Analysis of Subgroups
}

\author{
Antonio Gómez-Outes, ${ }^{1}$ Ana Isabel Terleira-Fernández, ${ }^{2,3}$ Gonzalo Calvo-Rojas, ${ }^{4}$ \\ M. Luisa Suárez-Gea, ${ }^{1}$ and Emilio Vargas-Castrillón ${ }^{2,3}$ \\ ${ }^{1}$ Division of Pharmacology and Clinical Evaluation, Medicines for Human Use, Spanish Agency for Medicines and Medical Devices \\ (AEMPS), c/Campezo 1, Edificio 8, 28022 Madrid, Spain \\ ${ }^{2}$ Department of Clinical Pharmacology, Hospital Clínico San Carlos, c/Prof. Martín Lagos s/n, 28040 Madrid, Spain \\ ${ }^{3}$ Department of Pharmacology, Universidad Complutense, Plaza Ramón y Cajal s/n, Ciudad Universitaria, 28040 Madrid, Spain \\ ${ }^{4}$ Department of Clinical Pharmacology, Hospital Clínic, University of Barcelona, c/Villarroel 170, 08036 Barcelona, Spain
}

Correspondence should be addressed to Antonio Gómez-Outes; agomezo@aemps.es

Received 26 June 2013; Accepted 11 September 2013

Academic Editor: Omer Iqbal

Copyright (c) 2013 Antonio Gómez-Outes et al. This is an open access article distributed under the Creative Commons Attribution License, which permits unrestricted use, distribution, and reproduction in any medium, provided the original work is properly cited.

\begin{abstract}
Background. New oral anticoagulants (NOAC; rivaroxaban, dabigatran, apixaban) have become available as an alternative to warfarin anticoagulation in non-valvular atrial fibrillation (NVAF). Methods. MEDLINE and CENTRAL, regulatory agencies websites, clinical trials registers and conference proceedings were searched to identify randomised controlled trials of NOAC versus warfarin in NVAF. Two investigators reviewed all studies and extracted data on patient and study characteristics along with cardiovascular outcomes. Relative risks (RR) and 95\% confidence intervals (CI) were estimated using a random effect metaanalysis. Results. Three clinical trials in 50,578 patients were included. The risk of non-hemorrhagic stroke and systemic embolic events (SEE) was similar with the NOAC and warfarin ( $\mathrm{RR}=0.93 ; 95 \% \mathrm{CI}=0.83-1.04)$, while the risk of intracranial bleeding (ICB) with the NOAC was lower than with warfarin $(\mathrm{RR}=0.46 ; 95 \% \mathrm{CI}=0.33-0.65)$. We found differences in the effect size on all strokes and SEE depending on geographic region as well as on non-hemorrhagic stroke, SEE, bleeding and mortality depending on time in therapeutic range. Conclusion. The NOAC seem no more effective than warfarin for prevention of nonhemorrhagic stroke and SEE in the overall NVAF population, but are generally associated with a lower risk of ICB than warfarin.
\end{abstract}

\section{Introduction}

Atrial fibrillation (AF) represents the most common sustained cardiac arrhythmia, affecting more than 6 million people in Europe $[1,2]$. AF, particularly when it is persistent/permanent, predisposes patients to the development of atrial thrombi, which may embolize to the systemic circulation, being associated with a 4 - to 5-fold increase in the risk of ischemic stroke [3].

Vitamin $\mathrm{K}$ antagonists (VKA; coumarins, like warfarin and acenocoumarol) have been the only oral anticoagulants available over the last 60 years [4]. These agents are effective to prevent stroke in patients with AF [5], but their management remains problematic due to their narrow therapeutic index and variability in drug exposure, necessitating routine coagulation monitoring (international normalised ratio (INR)), clinical surveillance, and continuous patient education [6]. As a result, approximately only half of eligible patients with AF receive oral anticoagulation with VKA [7].

Dabigatran etexilate (Pradaxa, Boehringer Ingelheim) [8], rivaroxaban (Xarelto, Bayer HealthCare) [9], and apixaban (Eliquis, Bristol Myers Squibb) [10] are new oral anticoagulants (NOAC) available in Europe and other countries. Unlike VKA, these new compounds exhibit a predictable dose response and do not require routine coagulation monitoring, but their anticoagulant effect declines quickly in case of 
poor compliance, and not coagulation monitoring tests or specific antidotes are currently available [4]. Among other indications, these new compounds have been tested for prophylaxis of stroke and systemic embolic events (SEE) in patients with nonvalvular atrial fibrillation (NVAF) using a combined primary outcome of all strokes (nonhemorrhagic and haemorrhagic) and SEE. The pivotal studies conducted in that indication are usually large clinical trials recruiting heterogeneous populations in different geographic regions [11]. The potential influence of differences in clinical, demographic, and geographic factors across studies on the relative efficacy and safety of the NOAC, as well as the clinical relevance of these differences, has not been thoroughly analysed. For that purpose, we systematically reviewed the data from randomised controlled trials with the NOAC for prevention of stroke and SEE in patients with NVAF.

\section{Methods}

2.1. Study Selection. We searched MEDLINE and CENTRAL (up to 31 December 2012), clinical trial registries, relevant conference proceedings, and regulatory agencies websites (see supplementary file for search strategy in Supplementary Material available at http://dx.doi.org/10.1155/2013/640723). No language restrictions were applied.

To maximize the real-world applicability of our results to relevant subgroups, we considered randomised phase III controlled trials with available subgroup analyses comparing any of the approved NOAC (i.e., rivaroxaban, dabigatran, and apixaban) with warfarin for prevention of stroke and SEE in patients with NVAF. At least one of the daily doses tested in the experimental arms had to correspond to the approved regime for the NOAC: dabigatran 150 or $110 \mathrm{mg}$ twice daily (BID), rivaroxaban $20 \mathrm{mg}$ once daily (OD), and apixaban $5 \mathrm{mg}$ BID. At least one of the drug control groups had to correspond to warfarin, dose adjusted to achieve a target INR of 2 to 3.

2.2. Data Extraction. Two investigators (Antonio GómezOutes and Ana Isabel Terleira-Fernández) independently and separately assessed trials for eligibility and extracted data. If a trial was covered in more than one report we used a hierarchy of data sources: public reports from regulatory authorities (US Food and Drug Administration, European Medicines Agency), peer-reviewed articles, reports from the web based repository for results of clinical studies, and other sources.

The following study characteristics were collected: number of patients; dosage of the experimental and control groups; trial phase and design; inclusion and exclusion criteria; main efficacy and safety outcomes; main populations and period of analyses; definition of noninferiority; adjudication committees of clinical events; median length followup; and time in therapeutic range (TTR). We assessed study quality using the Jadad scale [12]. Additionally, we used the Cochrane Collaboration's tool for assessing risk of bias in randomised studies [13].

The prespecified primary efficacy outcome was nonhemorrhagic (ischemic/undefined) stroke and SEE [14]. The main safety outcome was intracranial bleeding (ICB; composite of hemorrhagic stroke, subdural, subarachnoid, or epidural hemorrhage) [14]. A net clinical outcome was included as the composite of all strokes and SEE, which was consistent with the primary efficacy outcome in individual trials and in previous publications assessing the net clinical benefit of anticoagulant therapy [14]. A subanalysis of all strokes and SEE occurring after study drug discontinuation (i.e., temporary interruptions, permanent discontinuation, and after end of study) was also conducted. Other secondary outcomes included the components of the main efficacy and safety endpoints as well as major bleeding, major gastrointestinal bleeding, and mortality.

We collected outcome data on the overall trial populations as well as on the following 12 relevant subgroups: geographic region (Europe or other regions), prior stroke or transient ischemic attack (yes or no), quality of warfarin therapy (TTR $\geq 65 \%$ or $<65 \%$ ), degree of thromboembolic risk by applying the $\mathrm{CHADS}^{2}$ score ( $\geq 2$ or $<2$ score points), age ( $\geq 75$ yrs or $<75$ yrs), gender (male or female), diabetes (yes or no), heart failure (yes or no), renal function (creatinine clearance $\geq 50 \mathrm{~mL} / \mathrm{min}$ or $<50 \mathrm{~mL} / \mathrm{min}$ ), type of $\mathrm{AF}$ (permanent/persistent or paroxysmal), prior use of VKA (yes or no), and concomitant use of acetylsalicylic acid (yes or no). Finally, we contacted sponsors or the main investigators for missing outcome data of interest.

2.3. Statistical Analysis. We carried out direct comparisons between the NOAC and warfarin on an intention-to-treat basis, according to PRISMA (Preferred Reporting Items for Systematic Reviews and Meta-Analyses) recommendations [15].

For the meta-analysis we calculated relative and absolute risks and their respective 95\% confidence intervals (CI) for each study and for the pooled studies. Heterogeneity was assessed using the Cochran $Q$ test [16] and the Higgins $I^{2}$ test [17]. A Cochran's QP $P 0.10$ and $I^{2}>50 \%$ were considered to show significant heterogeneity between studies or subgroups [17]. We used the random effects model described by DerSimonian and Laird for the main analysis [18]. We carried out subgroup analyses according to relevant clinical characteristics (see "Outcome measures"). Pooled absolute risk estimates (obtained using risk difference meta-analysis) were annualized taking into account median followup during the studies. We also calculated the number needed to treat to benefit (NNTB) or to harm (NNTH) (as the inverse of the absolute risk difference) and corresponding confidence intervals for main outcomes [19]. We performed sensitivity analyses using the fixed effects method described by Mantel and Haenszel [20] and including only studies at low risk of bias. Baseline characteristics were compared across studies using Chi-square test for categorical variables and one-way analysis of variance (ANOVA) for continuous variables. Statistical calculations were done using the RevMan statistical software, version 5.1 (Nordic Cochrane Center) [21], and Microsoft Office Excel 2003 (Redmond, Washington; Microsoft Corporation, 2003). 


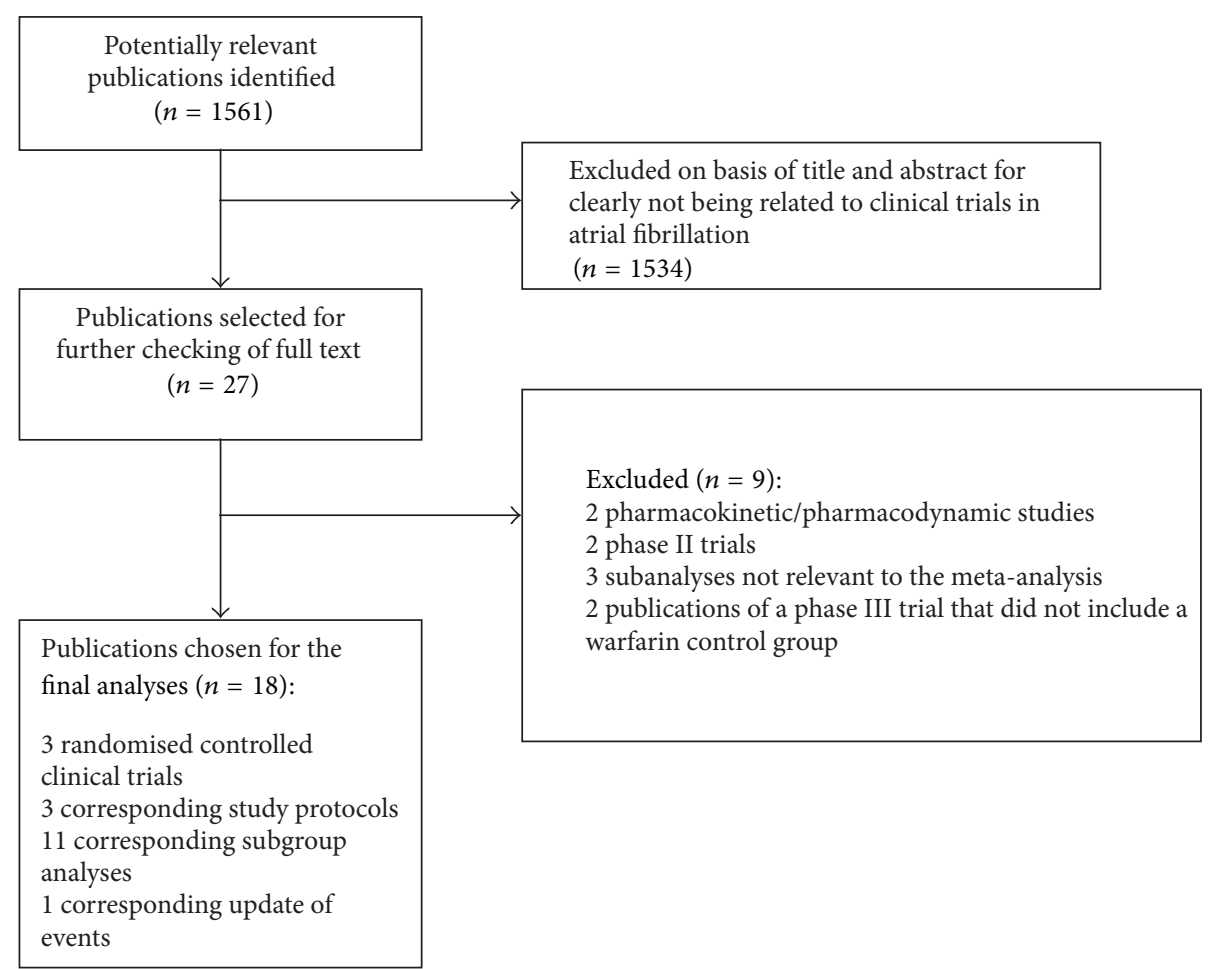

FIGURE 1: Study identification, selection, and exclusions.

\section{Results}

3.1. Descriptive Analysis. The literature search identified 1561 articles, 27 of which related to clinical trials or protocols with rivaroxaban, dabigatran, or apixaban in AF (Figure 1) and were selected for checking as full text. Three articles of phase III clinical trials with dabigatran (RE-LY study) [22], rivaroxaban (ROCKET-AF study) [23], and apixaban (ARISTOTLE study) [24] and their corresponding protocols [25-27] were eligible for inclusion. We also included 11 subanalyses of these trials that were considered relevant for the meta-analysis [28-38] and 1 article corresponding to update of events [39] reported in the RE-LY study [22]. The remaining 9 articles did not meet inclusion criteria and were excluded [40-48]. We also identified five public reports from the US Food and Drug Administration website [49-53] that included supplementary data of the RE-LY, ROCKET-AF, and ARISTOTLE studies, as well as one additional analysis of posttreatment events in the ROCKET-AF study [54] and one additional subanalysis of the ARISTOTLE study [55].

Table 1 shows the characteristics of the trials and treatments. The 3 studies comprised 50,578 patients and compared dabigatran $(n=12,091)$ [22], rivaroxaban $(n=7131)$ [23], or apixaban $(n=9120)$ [24] with warfarin $(n=22,236)$ [22-24]. In RE-LY, dabigatran was administered at fixed twice-daily doses of $150 \mathrm{mg}$ or $110 \mathrm{mg}$ [22]. On the contrary, in ROCKET$\mathrm{AF}$, the rivaroxaban $20 \mathrm{mg}$ OD dose had to be down-titrated to $15 \mathrm{mg}$ in patients with moderate renal impairment [23], while in ARISTOTLE, the apixaban $5 \mathrm{mg}$ BID dose had to be down-titrated to $2.5 \mathrm{mg}$ BID for patients with two or more of the following criteria: age $\geq 80$ years, body weight $\leq 60 \mathrm{~kg}$, and/or serum creatinine level $\geq 1.5 \mathrm{mg}$ per decilitre [24]. RELY scored 3 points on the Jadad scale and was considered to be at moderate risk of bias because it was an open study [22]. ROCKET-AF and ARISTOTLE were double-blind trials $[23,24]$, scoring 5 points on the Jadad scale, and were judged to be at low risk of bias. The risk-of-bias assessment following Cochrane recommendations [13] showed similar results, with RE-LY [22] considered to be at unclear risk of bias and ROCKET-AF [23] and ARISTOTLE [24] judged to be at low risk of bias (see supplementary Table A1).

Table 2 shows the characteristics of patients and events rates in the warfarin control group in each study. Median age ranged between 70 and 73 years across trials, with a predominance of male sex. However, other characteristics, like percentage of patients with $\mathrm{CHADS} \geq 2$, prior stroke/transient ischemic attack, congestive heart failure, age $>75$ years, type of AF, prior use of VKA or acetylsalicylic acid, and percent population enrolled in Europe, were widely heterogeneous. Demographic data were also compared for patients with prior stroke or transient ischemic attack (see supplementary Table A2) and a similar heterogeneity was found.

3.2. Primary Efficacy Outcome. The NOAC were not more effective than warfarin in preventing nonhemorrhagic stroke and SEE in the overall study populations $(\mathrm{RR}=0.93$; CI 0.83 to 1.04 ) (Figure 2). However, subgroup analyses suggest a trend towards superiority of the NOAC in centres with TTR $<65 \%$ (Figure 2). Approximately $92 \%$ of the events were nonhemorrhagic strokes and only $8 \%$ were SEE. The separate 
TABLE 1: Characteristics of the studies and treatments.

\begin{tabular}{|c|c|c|c|}
\hline Drug, trial & Dabigatran RE-LY $[22,48]$ & $\begin{array}{c}\text { Rivaroxaban ROCKET } \\
{[23,49]} \\
\end{array}$ & $\begin{array}{c}\text { Apixaban ARISTOTLE } \\
{[24,50]}\end{array}$ \\
\hline No. in sample & 18113 & 14264 & 18201 \\
\hline \multicolumn{4}{|l|}{ Treatment characteristics } \\
\hline Experimental drug & $\begin{array}{l}\text { Dabigatran } 150 \text { mg or } \\
110 \mathrm{mg} \text { twice daily }\end{array}$ & $\begin{array}{l}\text { Rivaroxaban } 20 \mathrm{mg} \text { or } \\
15 \mathrm{mg} \text { once daily }\end{array}$ & $\begin{array}{l}\text { Apixaban } 5 \mathrm{mg} \text { or } 2.5 \mathrm{mg} \\
\text { twice daily }\end{array}$ \\
\hline Experimental, $n$ & 12091 & 7131 & 9120 \\
\hline High-dose & 6076 & 5624 & 8702 \\
\hline Low-dose & 6015 & 1597 & 428 \\
\hline Control drug & $\begin{array}{l}\text { Warfarin dose-adjusted to } \\
\text { INR 2-3, once daily }\end{array}$ & $\begin{array}{l}\text { Warfarin dose-adjusted to } \\
\text { INR 2-3, once daily }\end{array}$ & $\begin{array}{l}\text { Warfarin dose-adjusted to } \\
\text { INR 2-3, once daily }\end{array}$ \\
\hline Control, $n$ & 6022 & 7133 & 9081 \\
\hline \multicolumn{4}{|l|}{ TTR (\%) } \\
\hline Mean & 64.4 & 55.2 & 62.2 \\
\hline Median & 67 & 58 & 66 \\
\hline Trial phase & III & III & III \\
\hline $\begin{array}{l}\text { Design of randomised controlled } \\
\text { trial }\end{array}$ & $\begin{array}{l}\text { Multicentre, open-label } \\
\text { PROBE }\end{array}$ & Multicentre, double-blind & Multicentre, double-blind \\
\hline $\begin{array}{l}\text { Adjudicating committee and } \\
\text { blinded adjudication of outcomes }\end{array}$ & Yes & Yes & Yes \\
\hline Interim analysis, $n$ & 2 & 1 & 1 \\
\hline Number of exclusion criteria & 14 & 31 & 19 \\
\hline Main efficacy outcome & Stroke and SEE & Stroke and SEE & Stroke and SEE \\
\hline Main analysis & Non-inferiority & Non-inferiority & Non-inferiority \\
\hline Non-inferiority margin & Relative risk $<1.46$ & Relative risk $<1.46$ & Relative risk $<1.38$ \\
\hline Main population of analysis & Intent-to-treat & Per protocol & Intent-to-treat \\
\hline Main period of analysis & $\begin{array}{l}\text { Until notification of study } \\
\text { termination }\end{array}$ & On-treatment plus 2 days & $\begin{array}{c}\text { Until notification of study } \\
\text { termination }\end{array}$ \\
\hline Main safety outcome & Major bleeding & Clinically relevant bleeding & Major bleeding \\
\hline Main population of analysis & Safety population & Safety population & Safety population \\
\hline Main period of analysis & On-treatment plus 6 days* & On-treatment plus 2 days* & On-treatment plus 2 days* \\
\hline Jadad Score & 3 & 5 & 5 \\
\hline Median length follow-up (days) & 730 & 707 & 657 \\
\hline
\end{tabular}

${ }^{*}$ After treatment discontinuation.

INR: international normalised ratio; PROBE: prospective, open-label, blinded endpoint; SEE: systemic embolic events; TTR: time in therapeutic range.

results for nonhemorrhagic stroke $(\mathrm{RR}=0.95$; CI 0.85 to 1.07) and SEE (RR $=0.73$; CI 0.50 to 1.07$)$ were consistent with those of the composite endpoint. The full subgroup analyses of the primary efficacy outcome are included in supplementary Figure A1.

3.3. Primary Safety Outcome. The NOAC reduced the relative risk of ICB in comparison with warfarin $(\mathrm{RR}=0.46$; $\mathrm{CI}$ 0.33 to 0.65 ) (Figure 3 ). However, there was a significant heterogeneity between the three studies due to a lower reduction of ICB by rivaroxaban in the ROCKET-AF study than by dabigatran or apixaban in the other studies $(P=$ $0.04 ; I^{2}=69 \%$ ) (Figure 3 ). The poorer effect of rivaroxaban versus warfarin on ICB was mainly observed in patients with prior stroke (Figure 3 ) and should be interpreted in line with the much lower rate of ICB with warfarin in this subpopulation of the ROCKET-AF study compared with the corresponding subpopulations of the RE-LY and ARISTOTLE studies (ROCKET-AF 1.24\% versus RE-LY 2.51\% versus ARISTOTLE $2.35 \%$; $P=0.0099$ ) (see supplementary Table A2). Approximately $60 \%$ of the ICB were hemorrhagic strokes and $40 \%$ corresponded to other types of ICB (e.g., subdural, subarachnoid, and epidural). The separate results for hemorrhagic stroke $(\mathrm{RR}=0.45$; $\mathrm{CI} 0.30$ to 0.66$)$ and other types of $\mathrm{ICB}(\mathrm{RR}=0.47$; CI 0.27 to 0.82$)$ were consistent with those of the composite endpoint.

\subsection{Secondary Outcomes}

3.4.1. All Strokes and Systemic Embolic Events (Intention-toTreat). In the overall study populations, the NOAC afforded a lower relative risk of events than warfarin $(\mathrm{RR}=0.82$; 
TABLE 2: Characteristics of the patients and events (overall study population).

\begin{tabular}{|c|c|c|c|c|}
\hline Drug, trial & $\begin{array}{c}\text { Dabigatran RE-LY } \\
{[22,48]}\end{array}$ & $\begin{array}{c}\text { Rivaroxaban } \\
\text { ROCKET }[23,49]\end{array}$ & $\begin{array}{c}\text { Apixaban } \\
\text { ARISTOTLE } \\
{[24,50]}\end{array}$ & $P$-value ${ }^{*}$ \\
\hline No in sample & 18113 & 14264 & 18201 & \\
\hline \multicolumn{5}{|l|}{ Patients characteristics } \\
\hline Age (years) & 72 (mean) & 73 (median) & 70 (median) & - \\
\hline Male gender & $11514(64 \%)$ & $8604(60 \%)$ & $5660(65 \%)$ & $<0.0001$ \\
\hline $\mathrm{CHADS}_{2}$ (mean \pm standard deviation) & $2.1 \pm 1.1$ & $3.46 \pm 0.95$ & $2.1 \pm 1.1$ & $<0.0001$ \\
\hline $\mathrm{CHADS}_{2} \geq 2$ & $12337(68 \%)$ & $14261(\approx 100 \%)$ & $12018(66 \%)$ & $<0.0001$ \\
\hline $\mathrm{CHADS}_{2}=1$ & $5775(32 \%)$ & $3(\approx 0 \%)$ & $6183(34 \%)$ & $<0.0001$ \\
\hline Prior stroke/transient ischemic attack & $3623(20 \%)$ & $7468(55 \%)$ & $3436(19 \%)$ & $<0.0001$ \\
\hline Congestive heart failure & $5793(32 \%)$ & $8908(63 \%)$ & $6451(35 \%)$ & $<0.0001$ \\
\hline Hypertension & $14283(79 \%)$ & $12910(91 \%)$ & $15916(87 \%)$ & $<0.0001$ \\
\hline Age $\geq 75$ years & $7238(40 \%)$ & $6229(43 \%)$ & $5678(31 \%)$ & $<0.0001$ \\
\hline Diabetes & $4221(23 \%)$ & $5695(40 \%)$ & $4547(25 \%)$ & $<0.0001$ \\
\hline Prior myocardial infarction & $3005(17 \%)$ & $2468(17 \%)$ & $2585(14 \%)$ & $<0.0001$ \\
\hline Patients in centers with TTR $\geq 65 \%$ & $8950(49 \%)$ & $3493(24 \%)$ & $9046(50 \%)$ & $<0.0001$ \\
\hline Patients recruited in Europe & $6770(37 \%)$ & $7582(53 \%)$ & $7343(40 \%)$ & $<0.0001$ \\
\hline Patients with $\mathrm{CrCl}<50 \mathrm{~mL} / \mathrm{min}$ & $3505(19 \%)$ & $2986(21 \%)$ & $3017(17 \%)$ & $<0.0001$ \\
\hline \multicolumn{5}{|l|}{ Type of atrial fibrillation } \\
\hline Permanent-persistent & $12164(67 \%)$ & $11548(81 \%)$ & $15412(85 \%)$ & $<0.0001$ \\
\hline Paroxysmal & $5943(33 \%)$ & $2514(18 \%)$ & $2786(15 \%)$ & $<0.0001$ \\
\hline \multicolumn{5}{|l|}{ Antithrombotic treatment at baseline } \\
\hline VKA & $8989(50 \%)$ & $8904(62 \%)$ & $10401(57 \%)$ & $<0.0001$ \\
\hline Acetylsalicylic acid & $7198(40 \%)$ & $5205(37 \%)$ & $5632(31 \%)$ & $<0.0001$ \\
\hline Event rate in the control group & $N=6022$ & $N=7133$ & $N=9081$ & \\
\hline Total stroke or SEE & $202(3.35 \%)$ & $306(4.29 \%)$ & $265(2.92 \%)$ & 0.0001 \\
\hline Ischemic stroke & $143(2.37 \%)$ & $226(3.17 \%)$ & $175(1.93 \%)$ & $<0.0001$ \\
\hline Hemorrhagic stroke & $45(0.75 \%)$ & $57(0.80 \%)$ & $78(0.75 \%)$ & 0.9968 \\
\hline SEE & $16(0.27 \%)$ & $25(0.35 \%)$ & $15(0.17 \%)$ & 0.2367 \\
\hline Intracranial bleeding & $90(1.49 \%)$ & $84(1.18 \%)$ & $122(1.34 \%)$ & 0.6421 \\
\hline Major bleeding & $421(6.99 \%)$ & $386(5.41 \%)$ & $462(5.09 \%)$ & $<0.0001$ \\
\hline Death & $487(8.09 \%)$ & $632(8.86 \%)$ & $669(7.37 \%)$ & 0.0168 \\
\hline Treatment discontinuation $^{\dagger}$ & $1150(19 \%)$ & $2468(35 \%)$ & $2732(30 \%)$ & $<0.0001$ \\
\hline
\end{tabular}

${ }^{*}$ Chi-square test for categorical variables and one-way analysis of variance (ANOVA) for continuous variables.

${ }^{\dagger}$ Treated patients that received assigned study drug but did not complete study.

$\mathrm{CrCl}$ : creatinine clearance; SEE: systemic embolic event; TTR: time in therapeutic range; VKA: vitamin K antagonist.

CI 0.74 to 0.91 ) (Figure 4). However, there were significant geographic differences. Within Europe, the NOAC did not significantly reduce the rates of events compared with warfarin, while outside of Europe the NOAC appeared superior in this regard (Figure 4). The full subgroup analyses of all strokes or SEE are included in supplementary Figure A3.

3.4.2. All Strokes and Systemic Embolic Events after Treatment. There was no statistically significant difference between the NOAC and warfarin in the risk of stroke and SEE after temporary interruptions or permanent discontinuations (Figure 5). However, after end of study, patients who were transitioned from the NOAC to warfarin experienced significantly more events within the first 30 days of transition than patients on the warfarin group ( $R R=3.87$; $C I 2.00$ to 7.51$)$ (Figure 5). The vast majority of events corresponded to ischemic/undefined stroke.

3.4.3. Major Bleeding and Deaths. There was a trend towards lower rates of major bleeding with the NOAC in comparison with warfarin in RE-LY and ARISTOTLE and neutral in ROCKET-AF (Figure 6). The trend towards reduction in major bleeding rates was homogeneous in patients with previous stroke or transient ischemic attack $(\mathrm{RR}=0.87$; CI 0.76 to 1.00$)$ and in patients recruited in Europe $(R R=0.86$; CI 0.75 to 0.99 ) (Figure 6). Between-subgroups significant 


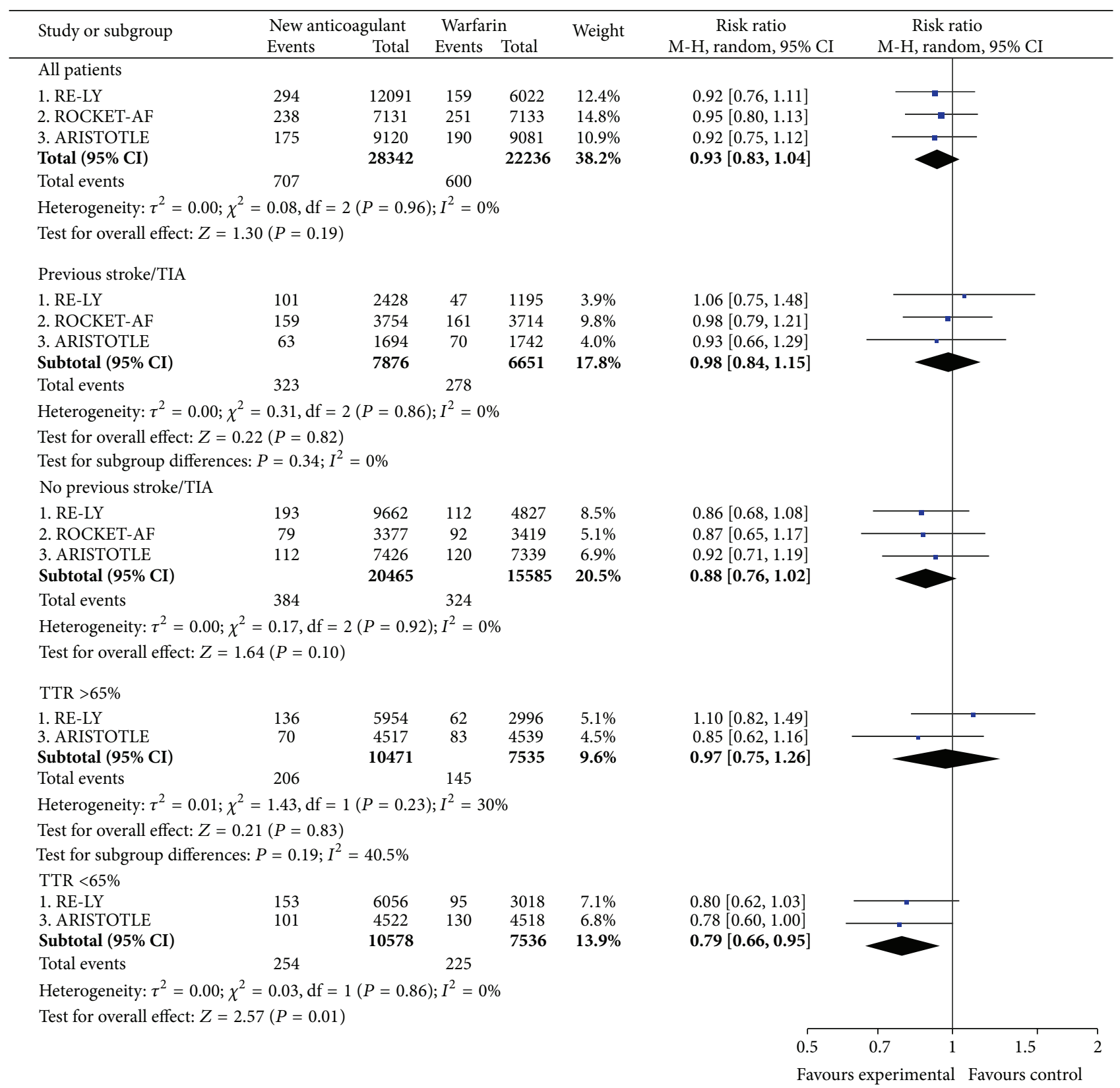

FIgURE 2: Nonhemorrhagic stroke and systemic embolic events.

heterogeneity was shown depending on TTR $(P=0.09$; $I^{2}=66 \%$ ), with better results of the NOAC on major bleeding in centres with TTR $<65 \%$ than in centres with TTR $\geq 65 \%$ (Figure 6). The full subgroup analyses of major bleeding are included in supplementary Figure A4.

There was a trend towards higher rates of major gastrointestinal bleeding with the NOAC in comparison with warfarin in RE-LY and ROCKET-AF and no increase in ARISTOTLE (Figure 7). Analysing the site of bleeding, rivaroxaban showed a trend towards increased risk of major upper gastrointestinal bleeding and major lower gastrointestinal bleeding, while dabigatran increased the risk of major lower gastrointestinal bleeding (Figure 7).
Overall, the NOAC reduced the risk of death in comparison with warfarin (Figure 8). However, the effect on death was heterogeneous depending on the TTR $\left(P=0.07 ; I^{2}\right.$ $=69.9 \%$ ), being nonsignificant in centres with TTR $\geq 65 \%$ $(\mathrm{RR}=0.97$; CI 0.87 to 1.09$)$ and significant in centres with TTR $<65 \%$ (RR $=0.85$; CI 0.76 to 0.93 ) (Figure 8). The full subgroup analyses of death are included in supplementary Figure A5.

3.5. Absolute Difference in Events per 1000 Patients Treated. Compared with warfarin, the NOAC did not avoid a significant number of nonhemorrhagic strokes or SEE events per 1000 patients treated in the overall study populations $(-1$; CI 


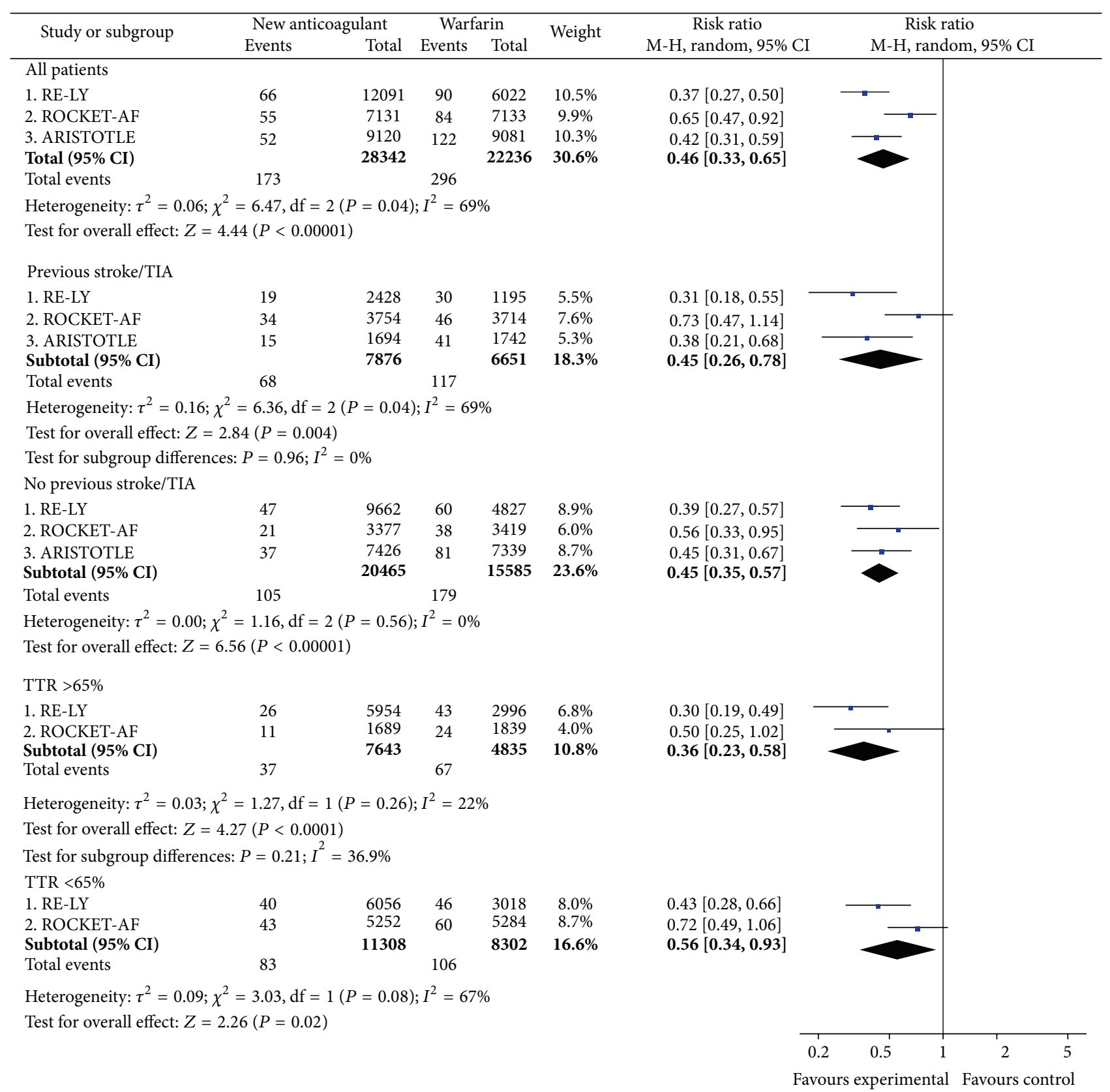

FIgURE 3: Intracranial bleeding.

-2.4 to 0.5 ) (Table 3). However, the reduction was significant in centres with TTR $<65 \%(-3.5$; CI -6.3 to -0.8$)$ (Table 3$)$.

The NOAC avoided a significant number of ICB in the overall study populations ( -3.7 ; CI -5.3 to -3.1 ) (NNTB per year, 271; CI 190 to 469), which was particularly relevant in patients with prior stroke or SEE $(-5.8$; CI -10.9 to -2.3$)$ (NNTB per year, 173; CI 92 to 437) (Table 3).

The numbers of all strokes and SEE avoided per 1000 patients per year were highly dependent on the geographic region and quality of warfarin therapy, with no significant differences in European patients or in centres with TTR $\geq 65 \%$. The absolute risk reduction in major bleedings was mainly observed in centres with TTR $<65 \%(-7.1$; CI -12.7 to -1.6 ) (Table 4).

The absolute risk difference in all-cause death per 1000 patients treated per year $(-3.90 ; \mathrm{CI}-6.34$ to -1.40$)$ was highly dependent on quality of warfarin therapy. No significant differences between the NOAC and warfarin were seen in centres with TTR $\geq 65 \%$ ( $-0.9 ;-4.8$ to 2.9$)$, while a significant absolute risk reduction was achieved in centres with TTR $<65 \%$ (-6.9; CI -11.2 to -2.6$)$.

3.6. Sensitivity Analyses. Sensitivity analyses using the fixed effects model and including only studies at low risk of bias 


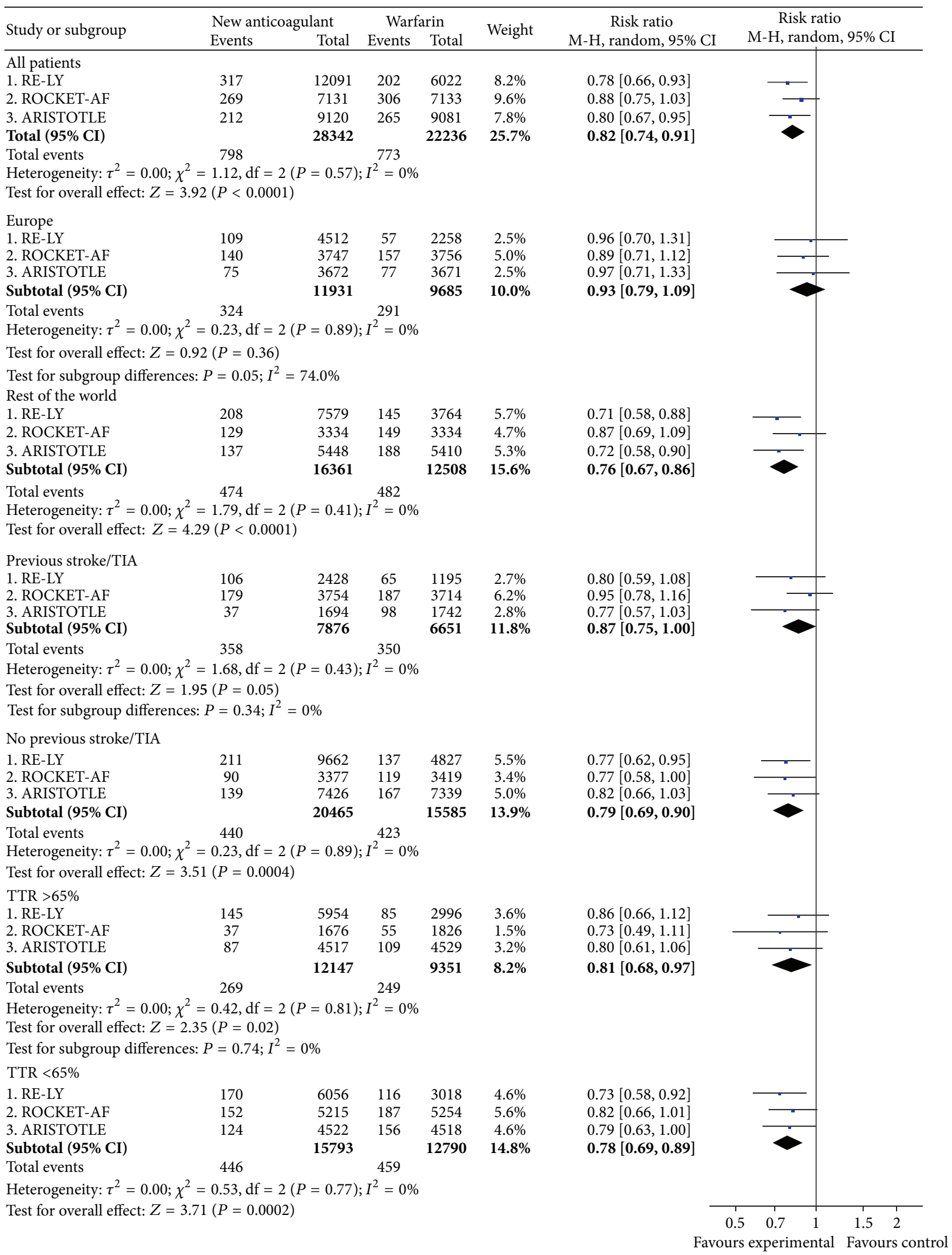

FIGURE 4: All strokes and systemic embolic events (intention-to-treat). 


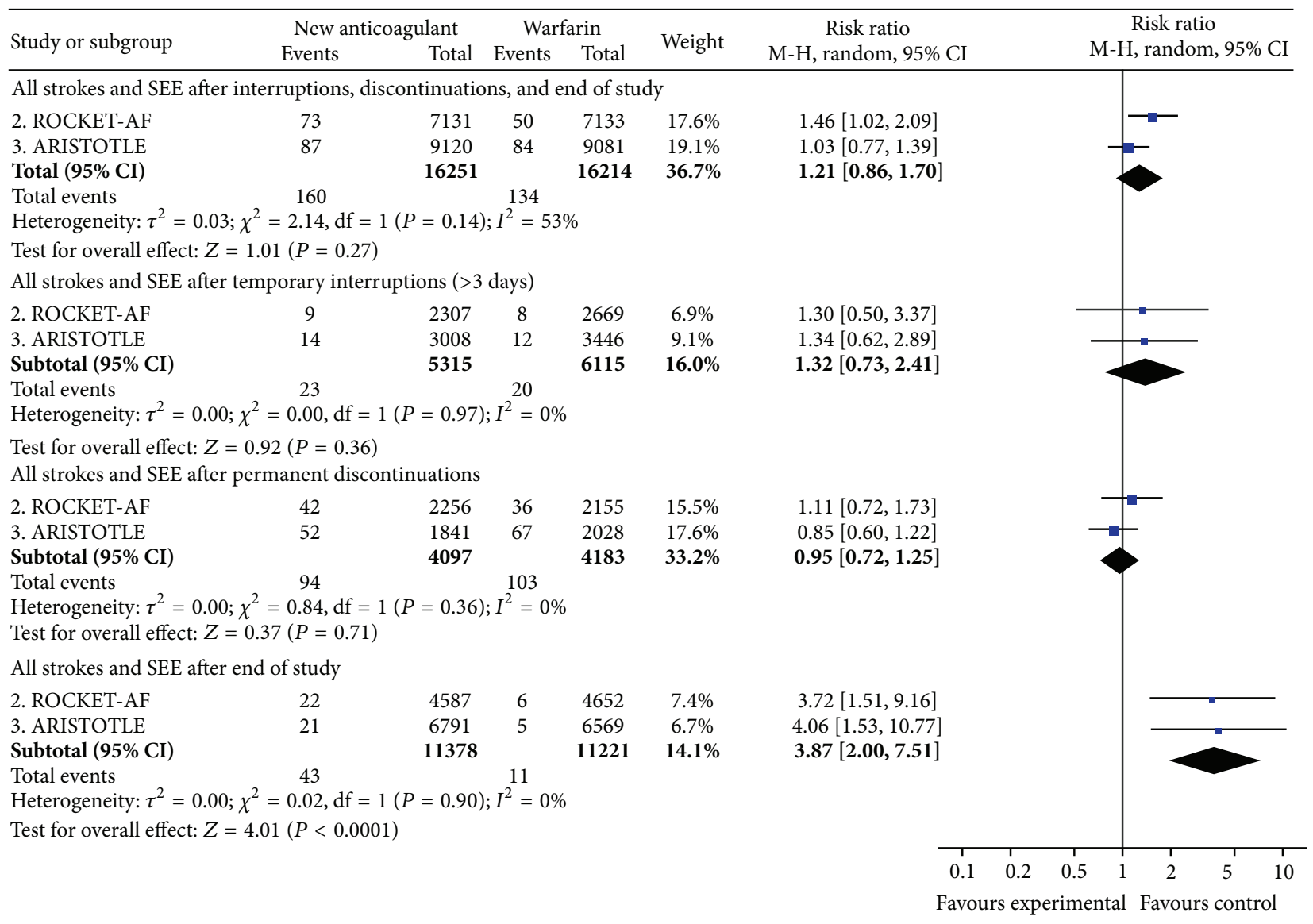

FIGURE 5: All strokes and systemic embolic events after study drug discontinuation.

were consistent with the main analysis (see supplementary Table A3).

3.7. Role of Funding. All studies were sponsored by pharmaceutical companies. In all cases, the sponsor was involved in the study design and oversight with the collaboration of a research institute and a scientific committee. In RE-LY [22], the Population Health Research Institute (Hamilton, ON, Canada) independently managed the database and performed the primary data analyses. In ROCKET-AF [23], the Duke Clinical Research Institute (Durham, NC, USA) coordinated the trial, managed the database, and performed the primary analyses independently of the sponsors. In ARISTOTLE [24], the primary analyses were performed both at Bristol-Myers Squibb and at the Duke Clinical Research Institute. At least one of the authors of the publications was employee of the sponsor.

\section{Discussion}

This systematic review, comprising more than fifty thousand patients enrolled in 3 randomised clinical trials, is to our knowledge the first systematic attempt to assess separately the efficacy of the NOAC in preventing thromboembolic events (nonhemorrhagic stroke and SEE) and major prohemorrhagic effects (ICB) [14] in NVAF. The data indicate that the NOAC have a generally similar efficacy than warfarin in the prevention of nonhemorrhagic stroke and SEE. This efficacy endpoint, which does not include hemorrhagic stroke, differs from the main outcome chosen for pivotal trials with NOAC in NVAF, which has been a net clinical endpoint including all strokes (ischemic, hemorrhagic, or undefined/unknown type) and SEE [22-24]. Our results are not inconsistent with the primary efficacy analyses of the respective studies but clearly suggest that, in the overall population, the weight of the effect tends to rely on the reduction of ICB, rather than on the antithromboembolic effect.

Two relevant meta-analyses of the NOAC in NVAF have been recently published $[56,57]$. These meta-analyses showed an overall clinical benefit of the NOAC versus warfarin in NVAF, which is consistent with the results of our metaanalysis regarding the net clinical endpoint of all strokes and SEE. With respect to the assessment of efficacy, there are some methodological differences between our meta-analysis and those conducted by Dentali et al. [56] and Miller et al. [57]. We analysed the composite of ischemic/undefined strokes and SEE, while the other meta-analyses only included ischemic strokes [56] or ischemic/undefined strokes [57]. Notwithstanding, the meta-analysis by Dentali et al. showed a similar efficacy of the NOAC and warfarin in preventing 


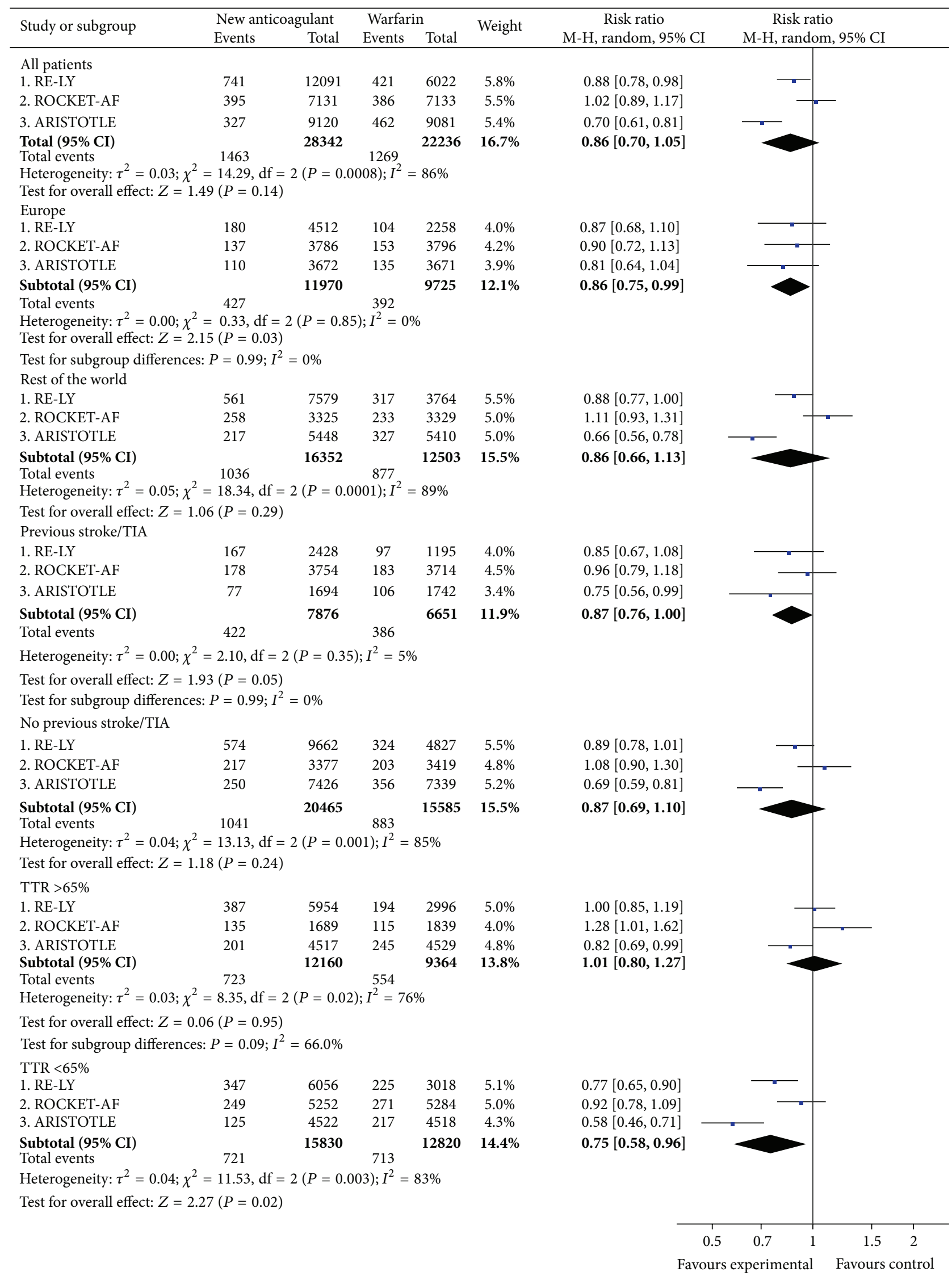

FIGURE 6: Major bleeding. 


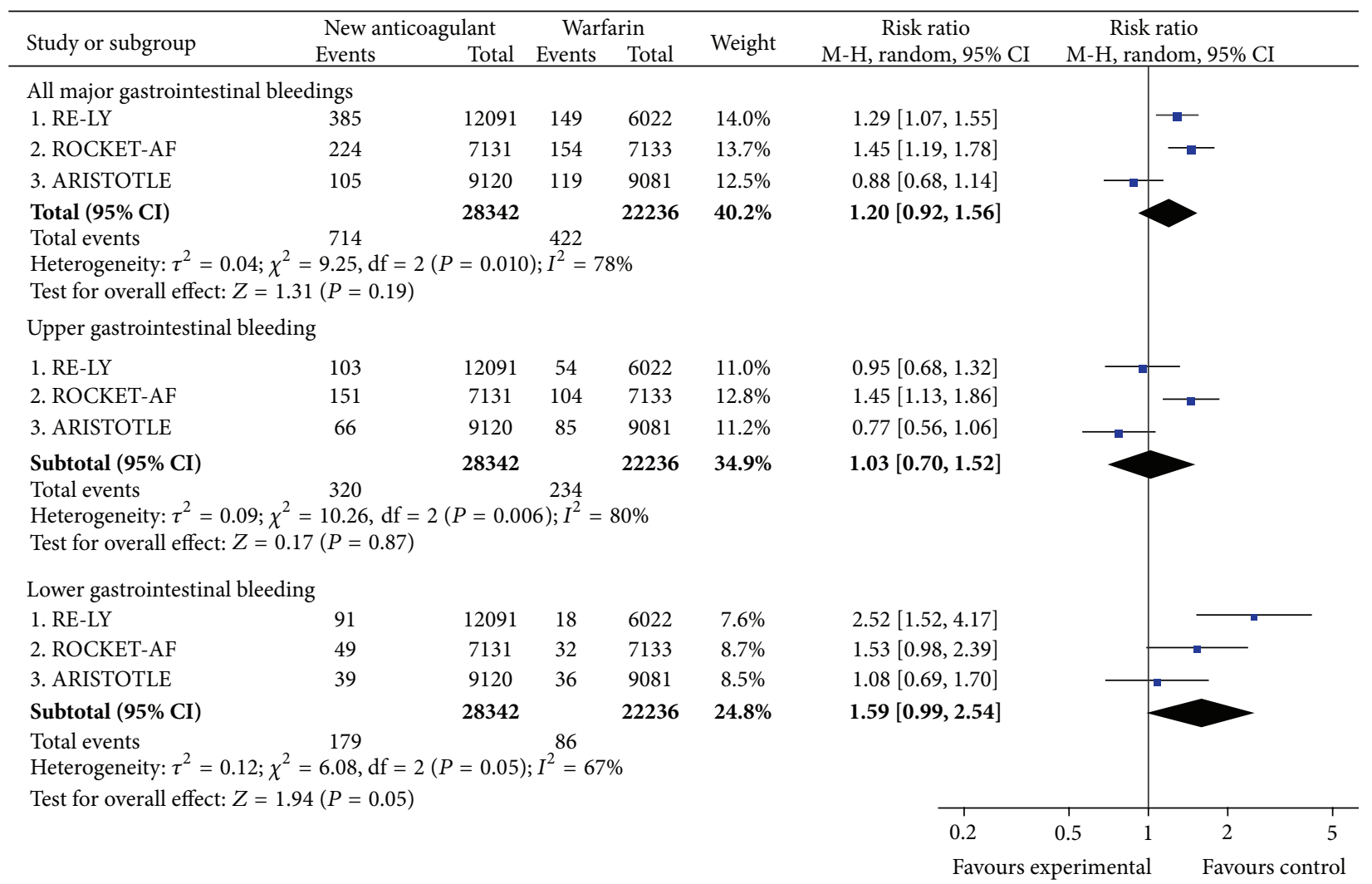

Figure 7: Major gastrointestinal bleeding.

ischemic stroke ( $\mathrm{RR}=0.92$; CI 0.81 to 1.04$)$ [56], which is consistent with the similar efficacy in preventing nonhaemorrhagic stroke and SEE found in our meta-analysis. On the other hand, the meta-analysis by Miller et al. [57] included the dabigatran $150 \mathrm{mg}$ BID dose but excluded the dabigatran $110 \mathrm{mg}$ BID dose, as the meta-analysis was conducted from a US perspective and the dabigatran $110 \mathrm{BID}$ dose is not currently approved in the US for use in NVAF. This issue could result in an overestimation of the efficacy of the NOAC versus warfarin in preventing ischemic/undefined strokes in their meta-analysis ( $R R=0.87$; CI 0.77 to 0.99$)$ [57]. On the contrary, we included both dabigatran doses (150 mg BID and $110 \mathrm{mg}$ BID), because both are already approved in Europe and many other regions for use in NVAF. The long-term extension of the RE-LY study has shown no differences in efficacy between the high and low dabigatran dose in the long term [58], which further supports our decision of including both dabigatran doses in the meta-analysis.

To the best of our knowledge, our systematic review is the first one that analyses specific subgroups and gives absolute risks estimates, thus providing a clear picture about the absolute benefit in efficacy or safety that may be expected with the NOAC in the heterogeneous population of patients with AF.

Although this review shows that the overall net clinical benefit of the NOAC versus warfarin is favourable, the magnitude of such benefit may be however influenced by a number of factors, as suggested by subgroup analyses. In RE-LY and
ARISTOTLE, superiority in the composite of all strokes and SEE was mainly gained at expenses of events that occurred in non-European countries (e.g., South America, Asia, and Africa), while all the NOAC were consistently not superior to warfarin in Europe. In the ROCKET study, with a higher proportion of European patients, these differences were not apparent. It is hard to believe that geography itself influences treatment effect, but it may influence the way patients are managed in clinical practice $[59,60]$. Potential interaction factors accounting for geographic differences may comprise the quality of oral anticoagulation and control of associated risk factors for thrombosis (e.g., hypertension, diabetes, and heart failure). The benefit of oral anticoagulation is largely dependent on the quality of INR control achieved by centers and countries as measured by TTR $[61,62]$. The use of centerbased TTRs as a proxy for individual-level INR control is a matter of controversy, but it may be considered a reasonable approach in clinical trials comparing the NOAC and warfarin in AF [28]. Individual-level comparisons between the NOAC and warfarin would increase the relevance of the results to decision-making, but these comparisons are very difficult to conduct given that there were no comparable INRs in the treatment arms with the NOAC. While the understanding of the determinants of individual TTR remains incomplete, it is clear that the providers of care, and the systems within which they work, have a profound effect on the quality of anticoagulation [63]. Beyond statistical significance, subgroup analyses suggest that the net benefit of the NOAC seems better than 


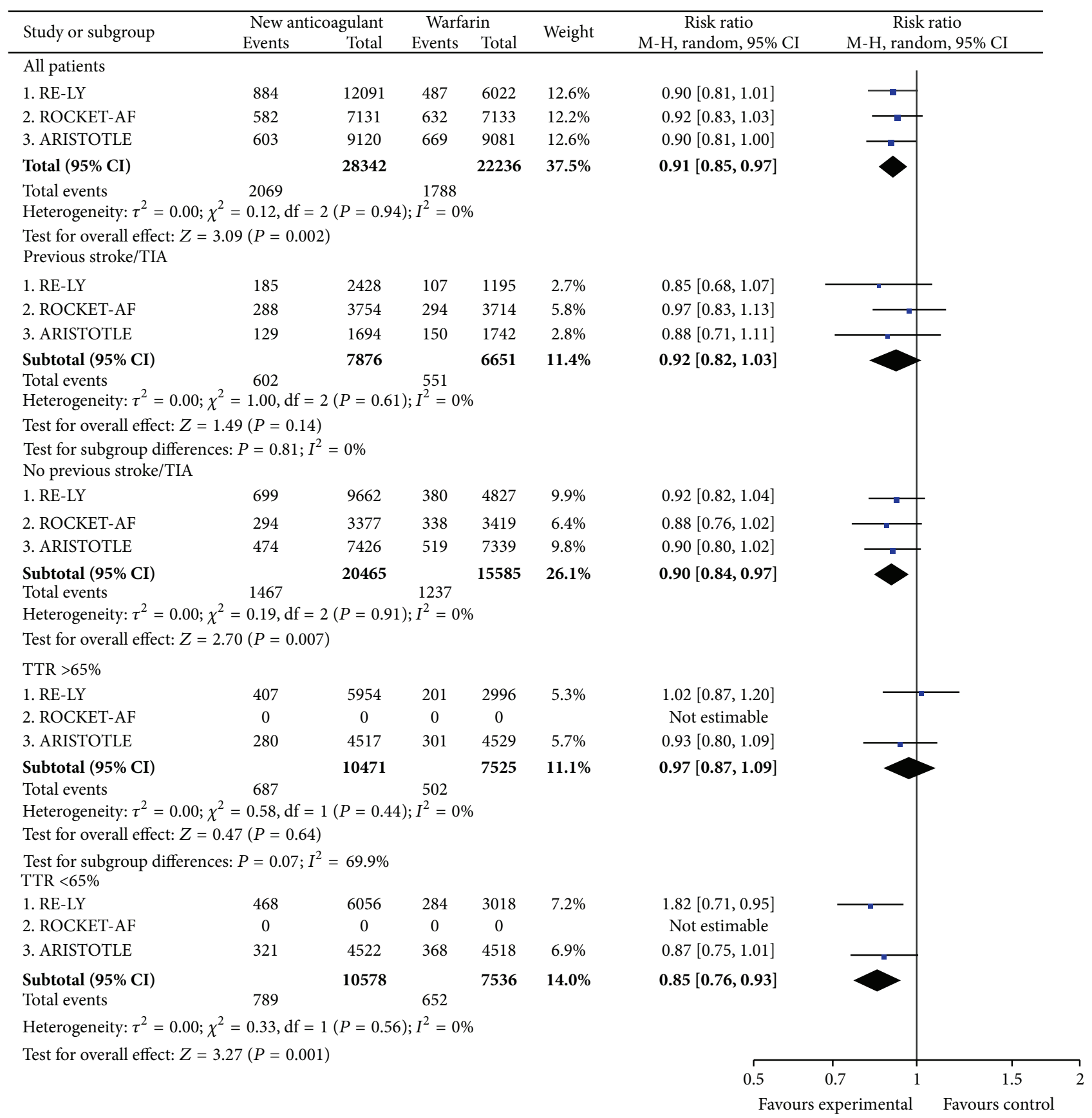

FIGURE 8: Mortality.

that of warfarin in situations in which quality of oral anticoagulation is poor, given that thromboembolic complications, major bleeding, and mortality may be decreased, as well as in patients with prior stroke or transient ischemic attack, particularly if they have concomitant predictive factors for developing ICB (e.g., leukoaraiosis) [64], given that the absolute risk reduction in ICB may be significant.

Switching between anticoagulants may be sometimes clinically indicated and have deleterious consequences if not properly planned. In ROCKET-AF and ARISTOTLE, an excess in (mainly ischemic) strokes occurred in the rivaroxaban and apixaban arms upon discontinuation at the end of the trial. This resumption of events was probably related to inadequate control of anticoagulation, but induction of a hypercoagulable state by long-term treatment with the NOAC has not been ruled out [51].

The present systematic review has limitations. The main efficacy outcome in our study (nonhemorrhagic stroke and SEE) was a part of the main net clinical outcome (all strokes and SEE) in individual studies. In addition, the 
TABLE 3: Direct comparisons for main outcomes: absolute difference in events per 1000 patients treated per year and NNTB per year*

\begin{tabular}{|c|c|c|c|c|}
\hline \multirow{2}{*}{$\begin{array}{l}\text { Population } \\
\text { Comparison }\end{array}$} & \multicolumn{2}{|c|}{ Non-hemorrhagic stroke and SEE } & \multicolumn{2}{|c|}{ Intracranial bleeding } \\
\hline & $\begin{array}{l}\text { Risk difference } \\
(95 \% \mathrm{CI})\end{array}$ & $\begin{array}{c}\text { NNTB } \\
(95 \% \mathrm{CI})\end{array}$ & $\begin{array}{l}\text { Risk difference } \\
\quad(95 \% \mathrm{CI})\end{array}$ & $\begin{array}{c}\text { NNTB } \\
(95 \% \mathrm{CI}) \\
\end{array}$ \\
\hline \multicolumn{5}{|l|}{ All patients } \\
\hline All NOAC versus warfarin & $-1(-2.4$ to 0.5$)$ & $\begin{array}{l}1012 \text { (NNTB } 418 \text { to } \infty \text { to } \\
\text { NNTH 2137) }\end{array}$ & $-3.7(-5.3$ to -3.1$)$ & $271(190$ to 469$)$ \\
\hline Dabigatran versus warfarin & $-1.1(-3.6$ to 1.4$)$ & $\begin{array}{l}934 \text { (NNTB } 280 \text { to } \infty \text { to } \\
\text { NNTH } 700)\end{array}$ & $-4.9(-6.5$ to -3.2$)$ & 206 (153 to 316$)$ \\
\hline Rivaroxaban versus warfarin & $-0.9(-4.1$ to 2.2$)$ & $\begin{array}{c}1068 \text { (NNTB } 247 \text { to } \infty \text { to } \\
\text { NNTH 458) }\end{array}$ & $-2.1(-3.8$ to -0.4$)$ & 469 (263 to 2404$)$ \\
\hline Apixaban versus warfarin & $-1.1(-2.6$ to 0.5$)$ & $\begin{array}{c}940 \text { (NNTB } 388 \text { to } \infty \text { to } \\
\text { NNTH 1984) }\end{array}$ & $-4.3(-5.9$ to -2.7$)$ & $232(168$ to 364$)$ \\
\hline \multicolumn{5}{|l|}{ Prior stroke or TIA } \\
\hline All NOAC versus warfarin & $-0.4(-3.8$ to 3$)$ & $\begin{array}{l}2404 \text { (NNTB } 263 \text { to } \infty \\
\text { to NNTH 332) }\end{array}$ & $-5.8(-10.9$ to -2.3$)$ & $173(92$ to 437$)$ \\
\hline Dabigatran versus warfarin & $1.2(-5.8$ to 8.1$)$ & $\begin{array}{c}853 \text { (NNTB } 174 \text { to } \infty \text { to } \\
\text { NNTH 123) }\end{array}$ & $-8.8(-13.7$ to -3.9$)$ & $113(73$ to 255$)$ \\
\hline Rivaroxaban versus warfarin & $-0.5(-5.3$ to 4.3$)$ & $\begin{array}{c}1923 \text { (NNTB } 189 \text { to } \infty \text { to } \\
\text { NNTH 235) }\end{array}$ & $-1.7(-4.2$ to 0.7$)$ & $\begin{array}{l}583 \text { (NNTB } 240 \text { to } \\
\infty \text { to NNTH 1479) }\end{array}$ \\
\hline Apixaban versus warfarin & $-1.7(-8.9$ to 5.5$)$ & $\begin{array}{c}595 \text { (NNTB } 112 \text { to } \infty \text { to } \\
\text { NNTH } 180 \text { ) }\end{array}$ & $-8.2(-12.9$ to -3.5$)$ & $121(77$ to 283$)$ \\
\hline \multicolumn{5}{|l|}{ No prior stroke or TIA } \\
\hline All NOAC versus warfarin & $-1.1(-2.7$ to 0.4$)$ & $\begin{array}{c}874 \text { (NNTB } 377 \text { to } \infty \text { to } \\
\text { NNTH 2747) }\end{array}$ & $-3.3(-4.3$ to -2.3$)$ & 305 (232 to 437$)$ \\
\hline Dabigatran versus warfarin & $-1.6(-4.2$ to 1$)$ & $\begin{array}{c}613 \text { (NNTB } 236 \text { to } \infty \text { to } \\
\text { NNTH 1032) }\end{array}$ & $-3.9(-5.6$ to -2.1$)$ & 258 (178 to 478$)$ \\
\hline Rivaroxaban versus warfarin & $-1.8(-5.7$ to 2$)$ & $\begin{array}{c}940 \text { (NNTB } 388 \text { to } \infty \text { to } \\
\text { NNTH 1984) }\end{array}$ & $-2.6(-4.8$ to -0.3$)$ & $392(207$ to 3846$)$ \\
\hline Apixaban versus warfarin & $-0.7(-3$ to 1.5$)$ & $\begin{array}{c}1374 \text { (NNTB } 337 \text { to } \infty \text { to } \\
\text { NNTH } 661)\end{array}$ & $-3.4(-5$ to -1.8$)$ & 293 (201 to 558$)$ \\
\hline \multicolumn{5}{|l|}{$T T R \geq 65 \%$} \\
\hline All NOAC versus warfarin & $-0.3(-3.0$ to 2.3$)$ & $\begin{array}{l}3086 \text { (NNTB } 337 \text { to } \infty \\
\text { to NNTH } 441)\end{array}$ & $-4.5(-6.4$ to -2.6$)$ & 223 (156 to 384$)$ \\
\hline Dabigatran versus warfarin & $1.1(-2.1$ to 4.3$)$ & $\begin{array}{l}\text { NNTH } 934 \text { (NNTB } 467 \\
\text { to } \infty \text { to NNTH 231) }\end{array}$ & $-5.1(-7.5$ to -2.8$)$ & $196(134$ to 363$)$ \\
\hline Rivaroxaban versus warfarin & NA & NA & $-3.4(-6.8$ to -0.1$)$ & 296 (148 to 19231$)$ \\
\hline Apixaban versus warfarin & $-1.6(-4.5$ to 1.4$)$ & $\begin{array}{c}638 \text { (NNTB } 220 \text { to } \infty \text { to } \\
\text { NNTH } 714 \text { ) }\end{array}$ & NA & NA \\
\hline \multicolumn{5}{|l|}{ TTR $<65 \%$} \\
\hline All NOAC versus warfarin & $-3.5(-6.3$ to -0.8$)$ & 283 (159 to 1190$)$ & $-2.9(-5.7$ to -0.2$)$ & $344(177$ to 6536$)$ \\
\hline Dabigatran versus warfarin & $-3.2(-6.9$ to 0.6$)$ & $\begin{array}{l}316 \text { (NNTB } 144 \text { to } \infty \text { to } \\
\text { NNTH 1751) }\end{array}$ & $-4.4(-6.9$ to -1.9$)$ & $228(145$ to 516$)$ \\
\hline Rivaroxaban versus warfarin & NA & NA & $-1.7(-3.6$ to 0.3$)$ & $\begin{array}{l}601 \text { (NNTB } 279 \text { to } \\
\infty \text { to NNTH 3205) }\end{array}$ \\
\hline Apixaban versus warfarin & $-3.6(-7.2$ to 0.1$)$ & $\begin{array}{c}279 \text { (NNTB } 138 \text { to } \infty \text { to } \\
\text { NNTH } 17857 \text { ) }\end{array}$ & NA & NA \\
\hline
\end{tabular}

${ }^{*}$ Random effects model, intention-to-treat.

NA: data not available; NNTB: number of patients needed to be treated for one additional patient to benefit; NNTH: number of patients needed to be treated for one additional patient to be harmed; NOAC: new oral anticoagulants; SEE: systemic embolic event; TIA: transient ischemic attack; TTR: time in therapeutic range. 
TABLE 4: Direct comparisons for secondary outcomes: absolute difference in events 1000 patients treated per year and NNTB per year*.

\begin{tabular}{|c|c|c|c|c|}
\hline \multirow{2}{*}{$\begin{array}{l}\text { Population } \\
\text { Comparison }\end{array}$} & \multicolumn{2}{|c|}{ All strokes and SEE } & \multicolumn{2}{|c|}{ Major bleeding } \\
\hline & $\begin{array}{l}\text { Risk difference } \\
(95 \% \mathrm{CI})\end{array}$ & $\begin{array}{c}\text { NNTB } \\
(95 \% \text { CI }) \\
\end{array}$ & $\begin{array}{l}\text { Risk difference } \\
(95 \% \mathrm{CI})\end{array}$ & $\begin{array}{c}\text { NNTB } \\
(95 \% \text { CI }) \\
\end{array}$ \\
\hline \multicolumn{5}{|l|}{ All patients } \\
\hline All NOAC versus warfarin & $-3.2(-4.8$ to -1.6$)$ & $310(207$ to 620$)$ & $-4(-9$ to 1$)$ & $\begin{array}{l}253 \text { (NNTB } 111 \text { to } \infty \\
\quad \text { to NNTH } 962)\end{array}$ \\
\hline Dabigatran versus warfarin & $-3.7(-6.5$ to -1$)$ & 269 (154 to 980$)$ & $-4.4(-8.4$ to -0.5$)$ & 228 (120 to 2179) \\
\hline Rivaroxaban versus warfarin & $-2.7(-6$ to 0.7$)$ & $\begin{array}{l}370(\text { NNTB } 166 \text { to } \infty \\
\text { to NNTH } 1479)\end{array}$ & $0.7(-3.2$ to 4.5$)$ & $\begin{array}{c}\text { NNTH } 1479 \text { (NNTB } \\
310 \text { to } \infty \text { to NNTH } \\
221)\end{array}$ \\
\hline Apixaban versus warfarin & $-3.3(-5.9$ to -0.7$)$ & 303 (168 to 1374$)$ & $-8.4(-11.7$ to -5.1$)$ & 119 (85 to 196$)$ \\
\hline \multicolumn{5}{|l|}{ European population } \\
\hline All NOAC versus warfarin & $-0.9(-3.1$ to 1.4$)$ & $\begin{array}{l}1131(\text { NNTB } 321 \text { to } \infty \\
\text { to NNTH 712) }\end{array}$ & $-3.0(-5.7$ to -0.3$)$ & 337 (176 to 3846$)$ \\
\hline Dabigatran versus warfarin & $-0.6(-4.6$ to 3.5$)$ & $\begin{array}{l}1783(\text { NNTB } 218 \text { to } \infty \\
\text { to NNTH } 288)\end{array}$ & $-3.2(-8.4$ to 2.1$)$ & $\begin{array}{l}316(\text { NNTB } 119 \text { to } \infty \\
\quad \text { to NNTH } 467)\end{array}$ \\
\hline Rivaroxaban versus warfarin & $-2.3(-7$ to 2.3$)$ & $\begin{array}{l}437 \text { (NNTB } 145 \text { to } \infty \\
\text { to NNTH } 437)\end{array}$ & $-2.1(-6.7$ to 2.3$)$ & $\begin{array}{l}469(\text { NNTB } 150 \text { to } \infty \\
\text { to NNTH } 427)\end{array}$ \\
\hline Apixaban versus warfarin & $-0.3(-4$ to 3.4$)$ & $\begin{array}{c}2976 \text { (NNTB } 252 \text { to } \\
\infty \text { to NNTH 298) }\end{array}$ & $-3.8(-8.4$ to 0.9$)$ & $\begin{array}{l}263(\text { NNTB } 119 \text { to } \infty \\
\text { to NNTH 1276) }\end{array}$ \\
\hline \multicolumn{5}{|l|}{ Non-European population } \\
\hline All NOAC versus warfarin & $-4.9(-7.1$ to -2.7$)$ & 205 (140 to 377$)$ & $-4.3(-12.5$ to 3.9$)$ & $\begin{array}{l}232(\text { NNTB } 80 \text { to } \infty \\
\text { to NNTH } 256)\end{array}$ \\
\hline Dabigatran versus warfarin & $-5.7(-9.3$ to -2$)$ & $177(108$ to 503$)$ & $-5.2(-10.7$ to 0.3$)$ & $\begin{array}{l}192(\text { NNTB } 94 \text { to } \infty \\
\text { to NNTH } 3922)\end{array}$ \\
\hline Rivaroxaban versus warfarin & $-3.1(-8.1$ to 1.9$)$ & $\begin{array}{l}321 \text { (NNTB } 123 \text { to } \infty \\
\text { to NNTH } 534)\end{array}$ & $4(-2.6$ to 10.5$)$ & $\begin{array}{l}\text { NNTH } 253 \text { (NNTB } \\
385 \text { to } \infty \text { to NNTH } \\
95)\end{array}$ \\
\hline Apixaban versus warfarin & $-5.4(-9$ to -1.8$)$ & $186(112$ to 558$)$ & $-11.5(-16.1$ to -6.9$)$ & $87(62$ to 144$)$ \\
\hline \multicolumn{5}{|l|}{ Prior stroke or TIA } \\
\hline All NOAC versus warfarin & $-3.6(-7.4$ to 0.1$)$ & $\begin{array}{l}275 \text { (NNTB } 135 \text { to } \infty \\
\quad \text { to NNTH } 19231)\end{array}$ & $-4.1(-8.7$ to 0.6$)$ & $\begin{array}{l}247 \text { (NNTB } 114 \text { to } \infty \\
\text { to NNTH 1603) }\end{array}$ \\
\hline Dabigatran versus warfarin & $-5.5(-13.2$ to 2.3$)$ & $\begin{array}{l}183(\text { NNTB } 76 \text { to } \infty \\
\text { to NNTH } 436)\end{array}$ & $-6.3(-15.8$ to 3.1$)$ & $\begin{array}{l}158(\text { NNTB } 63 \text { to } \infty \\
\text { to NNTH 321) }\end{array}$ \\
\hline Rivaroxaban versus warfarin & $-1.4(-6.5$ to 3.7$)$ & $\begin{array}{l}712(\text { NNTB } 154 \text { to } \infty \\
\text { to NNTH } 271)\end{array}$ & $-1(-6$ to 4.1$)$ & $\begin{array}{c}1012(\text { NNTB } 166 \text { to } \infty \\
\text { to NNTH } 243)\end{array}$ \\
\hline Apixaban versus warfarin & $-7.4(-15.5$ to 0.7$)$ & $\begin{array}{l}135(\text { NNTB } 64 \text { to } \infty \\
\text { to NNTH 1374) }\end{array}$ & $-8.6(-17$ to -0.2$)$ & $116(59$ to 4464$)$ \\
\hline \multicolumn{5}{|l|}{ No prior stroke or TIA } \\
\hline All NOAC versus warfarin & $-2.9(-4.6$ to -1.2$)$ & $350(219$ to 836$)$ & $-3.5(-9.1$ to 2$)$ & $\begin{array}{l}283(\text { NNTB } 111 \text { to } \infty \\
\text { to NNTH 506) }\end{array}$ \\
\hline Dabigatran versus warfarin & $-3.3(-6.2$ to -0.5$)$ & 302 (162 to 1961$)$ & $-3.9(-3.2$ to 0.4$)$ & $\begin{array}{l}255 \text { (NNTB } 316 \text { to } \infty \\
\text { to NNTH 2451) }\end{array}$ \\
\hline Rivaroxaban versus warfarin & $-4.3(-8.5$ to 0$)$ & $235(117$ to $\infty)$ & $2.6(-3.4$ to 8.5$)$ & $\begin{array}{c}\text { NNTH } 392(\text { NNTB } \\
291 \text { to } \infty \text { to NNTH } \\
118)\end{array}$ \\
\hline Apixaban versus warfarin & $-2.2(-4.8$ to 3.0$)$ & $\begin{array}{c}446(\text { NNTB } 208 \text { to } \infty \\
\text { to NNTH 2976) }\end{array}$ & $-8.3(-11.9$ to -0.5$)$ & $121(84$ to 213$)$ \\
\hline
\end{tabular}


TABLE 4: Continued.

\begin{tabular}{|c|c|c|c|c|}
\hline \multirow{2}{*}{$\begin{array}{l}\text { Population } \\
\text { Comparison }\end{array}$} & \multicolumn{2}{|c|}{ All strokes and SEE } & \multicolumn{2}{|c|}{ Major bleeding } \\
\hline & $\begin{array}{l}\text { Risk difference } \\
\quad(95 \% \text { CI })\end{array}$ & $\begin{array}{c}\text { NNTB } \\
(95 \% \mathrm{CI})\end{array}$ & $\begin{array}{l}\text { Risk difference } \\
\quad(95 \% \mathrm{CI})\end{array}$ & $\begin{array}{c}\text { NNTB } \\
(95 \% \text { CI })\end{array}$ \\
\hline \multicolumn{5}{|l|}{$T T R \geq 65 \%$} \\
\hline All NOAC versus warfarin & $-2.6(-4.8$ to -0.4$)$ & 385 (207 to 2404$)$ & $-0.6(-6.6$ to 7.7$)$ & $\begin{array}{c}\text { NNTH } 1748 \text { (NNTB } \\
153 \text { to } \infty \text { to NNTH } \\
130)\end{array}$ \\
\hline Dabigatran versus warfarin & $-2(-5.7$ to 1.6$)$ & $\begin{array}{l}490(\text { NNTB } 177 \text { to } \infty \\
\text { to NNTH } 633)\end{array}$ & $0.1(-5.4$ to 5.7$)$ & $\begin{array}{c}\text { NNTH } 9804 \text { (NNTB } \\
185 \text { to } \infty \text { to NNTH } \\
177)\end{array}$ \\
\hline Rivaroxaban versus warfarin & $-4.2(-9.7$ to 1.3$)$ & $\begin{array}{l}240(\text { NNTB } 103 \text { to } \infty \\
\text { to NNTH } 769)\end{array}$ & $9.1(0.2$ to 17.9$)$ & $\begin{array}{c}\text { NNTH } 111 \text { (56 to } \\
4808)\end{array}$ \\
\hline Apixaban versus warfarin & $-2.7(-6.1$ to 0.7$)$ & $\begin{array}{c}372(\text { NNTB } 165 \text { to } \infty \\
\text { to NNTH } 1488)\end{array}$ & $-5.4(-10.4$ to -0.4$)$ & $186(97$ to 2551$)$ \\
\hline \multicolumn{5}{|l|}{$T T R<65 \%$} \\
\hline All NOAC versus warfarin & $-4(-6.2$ to -1.9$)$ & $250(162$ to 534$)$ & $-7.1(-12.7$ to -1.6$)$ & $140(78$ to 641$)$ \\
\hline Dabigatran versus warfarin & $-5.3(-9.4$ to -1.2$)$ & $189(107$ to 853$)$ & $-8.8(-14.4$ to -3.2$)$ & 113 (69 to 316 ) \\
\hline Rivaroxaban versus warfarin & $-3.3(-6.9$ to 0.2$)$ & $\begin{array}{l}300(\text { NNTB } 146 \text { to } \infty \\
\text { to NNTH } 6410)\end{array}$ & $-2(-6.3$ to 2.3$)$ & $\begin{array}{l}493(\text { NNTB } 159 \text { to } \infty \\
\text { to NNTH } 437)\end{array}$ \\
\hline Apixaban versus warfarin & $-4(-8$ to 0$)$ & $252(126$ to $\infty)$ & $-11.4(-15.8$ to -7$)$ & 88 (63 to 143$)$ \\
\hline
\end{tabular}

${ }^{*}$ Random effects model, intention-to-treat.

NA: data not available; NNTB: number of patients needed to be treated for one additional patient to benefit; NNTH: number of patients needed to be treated for one additional patient to be harmed; NOAC: new oral anticoagulants; SEE: systemic embolic event; TIA: transient ischemic attack; TTR: time in therapeutic range.

main safety outcome in our study (ICB) was a secondary safety endpoint in individual studies. On the other hand, we conducted subgroup analyses, which have well-known limitations [65]. Testing multiple subgroups, even though prespecified, creates the possibility of false-positive findings. However, when subgroups are described in the protocol of the original trials along with a stated hypothesis, these secondary analyses may be used to illustrate applicability across patient subgroups [65, 66]. RE-LY, ROCKET-AF, and ARISTOTLE trials included a heterogeneous population (Table 2), and in such a situation, subgroup analyses are reasonable. In addition, most subgroups included a significant number of patients (e.g., 14,527 had prior stroke/TIA and 21,695 were recruited in European centers; Table 2) thus having sufficient statistical power to detect clinically meaningful differences between treatments.

At the time of translating the results from these clinical trials into practise, some additional considerations are necessary. On the one hand, thrombotic and haemorrhagic events in the real-world anticoagulated AF population are higher than those reported in clinical trials $[67,68]$, probably due to the strict selection of population and close followup applied in clinical trials. In particular, patients aged 75 years or older were underrepresented in clinical trials (range: $31 \%$ to $43 \%$ of patients) compared with real-world $\mathrm{AF}$ cohorts (range: $47 \%$ to $64 \%$ of patients) [69]. This issue may have important implications in bleeding risk, as renal function declines with age and all NOAC undergo renal elimination to a greater or lesser extent. Postmarketing reports of serious bleedings have frequently involved patients generally not qualified for the NOAC (i.e., severe renal insufficiency) [70]. This finding, accompanied by the current unavailability of specific antidotes, emphasizes the need for their appropriate use according to product labelling in order to minimise bleeding risk [8-10].

Finally, there is a need for strategies that could optimize anticoagulation quality and improve clinical outcomes in $\mathrm{AF}$ [71]. Beyond the use of NOAC in selected patients, these strategies may include systems facilitating algorithm-based warfarin dosing in the anticoagulation clinics [72], as well as the use of home-monitoring and self-management of anticoagulation with VKA in suitable candidates [73].

\section{Conclusion}

The NOAC seem no more effective than warfarin in preventing nonhemorrhagic stroke and SEE in NVAF. However, they are generally associated with a lower risk of ICB than warfarin. The net benefit of the NOAC seems better than that of warfarin in situations in which quality of oral anticoagulation is poor, given that thromboembolic complications, major bleeding, and mortality may be decreased, as well as patients with prior stroke or transient ischemic attack, as the absolute risk reduction in ICB may be particularly significant. However, the absolute benefit of the NOAC tends to be of a lesser magnitude in Europe than in other regions, which might be due to regional differences in quality of oral anticoagulation and overall management of associated risk factors for thrombosis. These findings would deserve further investigation. 


\section{Disclosure}

The contents of this study are solely the responsibility of the authors and do not necessarily represent the official view of their institutions or any other party.

\section{Conflict of Interests}

The authors declare that they have no conflict of interests.

\section{Authors' Contribution}

Antonio Gómez-Outes, Ana Isabel Terleira-Fernández, Gonzalo Calvo-Rojas, M. Luisa Suárez-Gea, and Emilio VargasCastrillón conceived and designed the study. Antonio Gómez-Outes and Ana Isabel Terleira-Fernández collected the data. Antonio Gómez-Outes carried out the statistical analysis and drafted the paper. Emilio Vargas-Castrillón supervised the study. All authors took part in the interpretation of the results and prepared the final version. Antonio Gómez-Outes and Emilio Vargas-Castrillón are responsible for the overall content as guarantors.

\section{References}

[1] A. J. Camm, P. Kirchhof, G. Y. Lip et al., "Guidelines for the management of atrial fibrillation: the Task Force for the Management of Atrial Fibrillation of the European Society of Cardiology (ESC)," European Heart Journal, vol. 31, no. 19, pp. 2369-2429, 2010.

[2] J. J. You, D. E. Singer, P. A. Howard et al., "Antithrombotic therapy for atrial fibrillation: antithrombotic therapy and prevention of thrombosis, 9th ed: american college of chest physicians evidence-based clinical practice guidelines," Chest, vol. 141, no. 2, pp. e531S-e575S, 2012.

[3] P. A. Wolf, R. D. Abbott, and W. B. Kannel, "Atrial fibrillation as an independent risk factor for stroke: the Framingham Study," Stroke, vol. 22, no. 8, pp. 983-988, 1991.

[4] A. Gómez-Outes, M. L. Suárez-Gea, G. Calvo-Rojas et al., "Discovery of anticoagulant drugs: a historical perspective," Current Drug Discovery Technologies, vol. 9, no. 2, pp. 83-104, 2012.

[5] R. G. Hart, L. A. Pearce, and M. I. Aguilar, "Meta-analysis: antithrombotic therapy to prevent stroke in patients who have nonvalvular atrial fibrillation," Annals of Internal Medicine, vol. 146, no. 12, pp. 857-867, 2007.

[6] J. Ansell, J. Hirsh, E. Hylek, A. Jacobson, M. Crowther, and G. Palareti, "Pharmacology and management of the vitamin K antagonists: American College of Chest Physicians EvidenceBased Clinical Practice Guidelines (8th Edition)," Chest, vol. 133, no. 6, pp. 160S-198S, 2008.

[7] L. Friberg, N. Hammar, M. Ringh, H. Pettersson, and M. Rosenqvist, "Stroke prophylaxis in atrial fibrillation: who gets it and who does not? Report from the Stockholm Cohort-study on Atrial Fibrillation (SCAF-study)," European Heart Journal, vol. 27, no. 16, pp. 1954-1964, 2006.

[8] European Medicines Agency, "Pradaxa-summary of product characteristics," 2013, http://www.ema.europa.eu/docs/en_ GB/document_library/EPAR_-_Product_Information/human/ 000829/000829/WC500041059.pdf.
[9] European Medicines Agency, "Xarelto-summary of product characteristics," 2013, http://www.ema.europa.eu/docs/en_ GB/document_library/EPAR_-_Product_Information/human/ 000944/WC500057108.pdf.

[10] European Medicines Agency, "Eliquis-summary of product characteristics," 2013, http://www.ema.europa.eu/docs/en GB/document_library/EPAR_-_Product_Information/human/ 002148/sWC500107728.pdf.

[11] G. Calvo-Rojas and A. Gémez-Outes, "Clinical drug development in thromboembolic diseases: regulatory and methodological approach," Current Drug Discovery Technologies, vol. 9, no. 2, pp. 105-118, 2012.

[12] A. R. Jadad, R. A. Moore, D. Carroll et al., "Assessing the quality of reports of randomized clinical trials: is blinding necessary?" Controlled Clinical Trials, vol. 17, no. 1, pp. 1-12, 1996.

[13] J. P. Higgins, D. G. Altman, P. C. Gøtzsche et al., "The Cochrane Collaboration's tool for assessing risk of bias in randomised trials," British Medical Journal, vol. 343, Article ID d5928, 2011.

[14] D. E. Singer, Y. Chang, M. C. Fang et al., "The net clinical benefit of warfarin anticoagulation in atrial fibrillation," Annals of Internal Medicine, vol. 151, no. 5, pp. 297-305, 2009.

[15] A. Liberati, D. G. Altman, J. Tetzlaff et al., "The PRISMA statement for reporting systematic reviews and meta-analyses of studies that evaluate healthcare interventions: explanation and elaboration," British Medical Journal, vol. 339, Article ID b2700, 2009.

[16] W. G. Cochran, "The combination of estimates from different experiments," Biometrics, vol. 10, no. 1, pp. 101-129, 1954.

[17] J. P. T. Higgins, S. G. Thompson, J. J. Deeks, and D. G. Altman, "Measuring inconsistency in meta-analyses," British Medical Journal, vol. 327, no. 7414, pp. 557-560, 2003.

[18] R. DerSimonian and N. Laird, "Meta-analysis in clinical trials," Controlled Clinical Trials, vol. 7, no. 3, pp. 177-188, 1986.

[19] D. G. Altman, "Confidence intervals for the number needed to treat," British Medical Journal, vol. 317, no. 7168, pp. 1309-1312, 1998.

[20] N. Mantel and W. Haenszel, "Statistical aspects of the analysis of data from retrospective studies of disease," Journal of the National Cancer Institute, vol. 22, no. 4, pp. 719-748, 1959.

[21] The Nordic Cochrane Centre, The Cochrane Collaboration, Review Manager (RevMan) [Computer program]. Version 5. 1, Copenhagen, 2011.

[22] S. J. Connolly, M. D. Ezekowitz, S. Yusuf et al., "Dabigatran versus warfarin in patients with atrial fibrillation," The New England Journal of Medicine, vol. 361, no. 12, pp. 1139-1151, 2009.

[23] M. R. Patel, K. W. Mahaffey, J. Garg et al., "Rivaroxaban versus warfarin in nonvalvular atrial fibrillation," The New England Journal of Medicine, vol. 365, no. 10, pp. 883-891, 2011.

[24] C. B. Granger, J. H. Alexander, J. J. V. McMurray et al., "Apixaban versus warfarin in patients with atrial fibrillation," The New England Journal of Medicine, vol. 365, no. 11, pp. 981-992, 2011.

[25] M. D. Ezekowitz, S. Connolly, A. Parekh et al., "Rationale and design of RE-LY: randomized evaluation of long-term anticoagulant therapy, warfarin, compared with dabigatran," American Heart Journal, vol. 157, no. 5, pp. 805.e2-810.e2, 2009.

[26] ROCKET AF Study Investigators, "Rivaroxaban-once daily, oral, direct factor $\mathrm{Xa}$ inhibition compared with vitamin $\mathrm{K}$ antagonism for prevention of stroke and Embolism Trial in Atrial Fibrillation: rationale and design of the ROCKET AF Study," American Heart Journal, vol. 159, no. 3, pp. 340-347, 2010. 
[27] R. D. Lopes, J. H. Alexander, S. M. Al-Khatib et al., "Apixaban for Reduction in Stroke and other Thromboembolic Events in Atrial Fibrillation (ARISTOTLE) trial: design and rationale," American Heart Journal, vol. 159, no. 3, pp. 331-339, 2010.

[28] L. Wallentin, S. Yusuf, M. D. Ezekowitz et al., "Efficacy and safety of dabigatran compared with warfarin at different levels of international normalised ratio control for stroke prevention in atrial fibrillation: an analysis of the RE-LY trial," The Lancet, vol. 376, no. 9745, pp. 975-983, 2010.

[29] H.-C. Diener, S. J. Connolly, M. D. Ezekowitz et al., "Dabigatran compared with warfarin in patients with atrial fibrillation and previous transient ischaemic attack or stroke: a subgroup analysis of the RE-LY trial," The Lancet Neurology, vol. 9, no. 12, pp. 1157-1163, 2010.

[30] M. D. Ezekowitz, L. Wallentin, S. J. Connolly et al., "Dabigatran and warfarin in vitamin $\mathrm{K}$ antagonist-naive and -experienced cohorts with atrial fibrillation," Circulation, vol. 122, no. 22, pp. 2246-2253, 2010.

[31] J. W. Eikelboom, L. Wallentin, S. J. Connolly et al., "Risk of bleeding with 2 doses of dabigatran compared with warfarin in older and younger patients with atrial fibrillation: an analysis of the randomized evaluation of long-term anticoagulant therapy (RE-LY) Trial," Circulation, vol. 123, no. 21, pp. 2363-2372, 2011.

[32] J. Oldgren, M. Alings, H. Darius et al., "Risks for stroke, bleeding, and death in patients with atrial fibrillation receiving dabigatran or warfarin in relation to the CHADS2 score: a subgroup analysis of the Re-Ly trial," Annals of Internal Medicine, vol. 155, no. 10, pp. 660-667, 2011.

[33] G. Flaker, M. Ezekowitz, S. Yusuf et al., "Efficacy and safety of dabigatran compared to warfarin in patients with paroxysmal, persistent, and permanent atrial fibrillation: results from the RE-LY (Randomized Evaluation of Long-Term Anticoagulation Therapy) study," Journal of the American College of Cardiology, vol. 59, no. 9, pp. 854-855, 2012.

[34] S. H. Hohnloser, J. Oldgren, S. Yang et al., "Myocardial ischemic events in patients with atrial fibrillation treated with dabigatran or warfarin in the RE-LY (Randomized evaluation of long-term anticoagulation therapy) trial," Circulation, vol. 125, no. 5, pp. 669-676, 2012.

[35] K. A. A. Fox, J. P. Piccini, D. Wojdyla et al., "Prevention of stroke and systemic embolism with rivaroxaban compared with warfarin in patients with non-valvular atrial fibrillation and moderate renal impairment," European Heart Journal, vol. 32, no. 19, pp. 2387-2394, 2011.

[36] G. J. Hankey, M. R. Patel, S. R. Stevens et al., "Rivaroxaban compared with warfarin in patients with atrial fibrillation and previous stroke or transient ischaemic attack: a subgroup analysis of ROCKET AF,' The Lancet Neurology, vol. 11, no. 4, pp. 315-322, 2012.

[37] J. D. Easton, R. D. Lopes, M. C. Bahit et al., "Apixaban compared with warfarin in patients with atrial fibrillation and previous stroke or transient ischaemic attack: a subgroup analysis of the ARISTOTLE trial," The Lancet Neurology, vol. 11, no. 6, pp. 5035511, 2012.

[38] R. D. Lopes, S. M. Al-Khatib, L. Wallentin et al., "Efficacy and safety of apixaban compared with warfarin according to patient risk of stroke and of bleeding in atrial fibrillation: a secondary analysis of a randomised controlled trial," The Lancet, vol. 380, no. 9855, pp. 1749-1758, 2012.

[39] S. J. Connolly, M. D. Ezekowitz, S. Yusuf, P. A. Reilly, and L. Wallentin, "Newly identified events in the RE-LY trial," The New England Journal of Medicine, vol. 363, no. 19, pp. 1875-1876, 2010.
[40] R. Nagarakanti, M. D. Ezekowitz, J. Oldgren et al., "Dabigatran versus warfarin in patients with atrial fibrillation: an analysis of patients undergoing cardioversion," Circulation, vol. 123, no. 2, pp. 131-136, 2011.

[41] M. Hori, S. J. Connolly, M. D. Ezekowitz, P. A. Reilly, S. Yusuf, and L. Wallentin, "Efficacy and safety of dabigatran vs. warfarin in patients with atrial fibrillation: sub-analysis in Japanese population in RE-LY trial," Circulation Journal, vol. 75, no. 4, pp. 800-805, 2011.

[42] H.-C. Diener, J. Eikelboom, S. J. Connolly et al., "Apixaban versus aspirin in patients with atrial fibrillation and previous stroke or transient ischaemic attack: a predefined subgroup analysis from AVERROES, a randomised trial," The Lancet Neurology, vol. 11, no. 3, pp. 225-231, 2012.

[43] K.-H. Liesenfeld, T. Lehr, C. Dansirikul et al., "Population pharmacokinetic analysis of the oral thrombin inhibitor dabigatran etexilate in patients with non-valvular atrial fibrillation from the RE-LY trial," Journal of Thrombosis and Haemostasis, vol. 9, no. 11, pp. 2168-2175, 2011.

[44] W. Mueck, A. W. A. Lensing, G. Agnelli, H. Decousus, P. Prandoni, and F. Misselwitz, "Rivaroxaban: population pharmacokinetic analyses in patients treated for acute deep-vein thrombosis and exposure simulations in patients with atrial fibrillation treated for stroke prevention," Clinical Pharmacokinetics, vol. 50, no. 10, pp. 675-686, 2011.

[45] M. D. Ezekowitz, P. A. Reilly, G. Nehmiz et al., "Dabigatran with or without concomitant aspirin compared with warfarin alone in patients with nonvalvular atrial fibrillation (petro study)," American Journal of Cardiology, vol. 100, no. 9, pp. 1419-1426, 2007.

[46] S. Ogawa, Y. Shinohara, and K. Kanmuri, "Safety and efficacy of the oral direct factor Xa inhibitor apixaban in Japanese patients with non-valvular atrial fibrillation," Circulation Journal, vol. 75, no. 8, pp. 1852-1859, 2011.

[47] S. J. Connolly, J. Eikelboom, C. Joyner et al., "Apixaban in patients with atrial fibrillation," The New England Journal of Medicine, vol. 364, no. 9, pp. 806-817, 2011.

[48] J. W. Eikelboom, M. O’Donnell, S. Yusuf et al., "Rationale and design of AVERROES: apixaban versus acetylsalicylic acid to prevent stroke in atrial fibrillation patients who have failed or are unsuitable for vitamin K antagonist treatment," American Heart Journal, vol. 159, no. 3, pp. 348.e1-353.e1, 2010.

[49] FDA Briefing Information, Dabigatran Etexilate Mesylate Capsules, for the September 20, 2010 Meeting of the Cardiovascular and Renal Drugs Advisory Committee, 2013, http:// www.fda.gov/downloads/AdvisoryCommittees/CommitteesMeetingMaterials/Drugs/CardiovascularandRenalDrugsAdvisoryCommittee/UCM247244.pdf.

[50] "FDA Briefing Information for the September 8, 2011 Meeting of the Cardiovascular and Renal Drugs Advisory Committee," 2013, http://www.fda.gov/downloads/AdvisoryCommittees/ CommitteesMeetingMaterials/Drugs/CardiovascularandRenalDrugsAdvisoryCommittee/UCM270796.pdf.

[51] FDA. Apixaban Clinical Review Addendum. December 17, 2012, http://www.accessdata.fda.gov/drugsatfda_docs/nda/2012/ 202155Orig1s000MedR.pdf.

[52] Boehringer Ingelheim Briefing Information, "Dabigatran Etexilate Mesylate Capsules, for the September 20, 2010 Meeting of the Cardiovascular and Renal Drugs Advisory Committee," 2013, http://www.fda.gov/downloads/AdvisoryCommittees/ CommitteesMeetingMaterials/Drugs/CardiovascularandDrugsAdvisoryCommittee/UCM226009.pdf. 
[53] "Johnson \& Johnson Briefing Information for the September 8, 2011 Meeting of the Cardiovascular and Renal Drugs Advisory Committee," http://www.fda.gov/downloads/AdvisoryCommittees/CommitteesMeetingMaterials/Drugs/CardiovascularandRenalDrugsAdvisoryCommittee/UCM270797.pdf.

[54] M. R. Patel, A. S. Hellkamp, Y. Lokhnygina et al., "Outcomes of discontinuing rivaroxaban compared with warfarin in patients with nonvalvular atrial fibrillation: analysis from the ROCKET AF trial (Rivaroxaban Once-Daily, Oral, Direct Factor Xa Inhibition Compared With Vitamin K Antagonism for Prevention of Stroke and Embolism Trial in Atrial Fibrillation)," Journal of the American College of Cardiology, vol. 61, no. 6, pp. 651-658, 2013.

[55] L. Wallentin, R. D. Lopes, M. Hanna et al., "ARISTOTLE: efficacy and safety of apixaban compared with Warfarin at different levels of INR control for stroke prevention in 18, 202 patients with atrial fibrillation in the ARISTOTLE trial," Presentation at the European Society of Cardiology (ESC) Congress 2011. Paris, August 27-31, 2011, http://www.escardio.org/congresses/esc2011/congress-reports/Pages/709-3-ARISTOTLE.aspx.

[56] F. Dentali, N. Riva, M. Crowther et al., "Efficacy and safety of the novel oral anticoagulants in atrial fibrillation: a systematic review and meta-analysis of the literature," Circulation, vol. 126, no. 20, pp. 2381-2391, 2012.

[57] C. S. Miller, S. M. Grandi, A. Shimony, K. B. Filion, and M. J. Eisenberg, "Meta-analysis of efficacy and safety of new oral anticoagulants (Dabigatran, Rivaroxaban, Apixaban) versus warfarin in patients with atrial fibrillation," American Journal of Cardiology, vol. 110, no. 3, pp. 453-460, 2012.

[58] J. W. Eikelboom, S. J. Connolly, R. G. Hart et al., "Balancing the benefits and risks of two doses of dabigatran compared with warfarin in atrial fibrillation," Journal of the American College of Cardiology, vol. 62, no. 10, pp. 900-908, 2013.

[59] J. F. Meschia, P. Merrill, E. Z. Soliman et al., "Racial disparities in awareness and treatment of atrial fibrillation: the REasons for geographic and racial differences in stroke (REGARDS) study," Stroke, vol. 41, no. 4, pp. 581-587, 2010.

[60] J. S. Healey, G. Y. Lip, J. Oldgren et al., "Global variations in the 1-year rates of death and stroke in 15, 340 patients presenting to the emergency department with atrial fibrillation in 47 countries: the RE-LY AF Registry, " Presentation at the European Society of Cardiology (ESC) Congress 2012, Munich, August 25-29," 2012, http://www.escardio.org/congresses/esc2012/congress-reports/Pages/711-3-RELY-AF.aspx .

[61] S. J. Connolly, J. Pogue, J. Eikelboom et al., "Benefit of oral anticoagulant over antiplatelet therapy in atrial fibrillation depends on the quality of international normalized ratio control achieved by centers and countries as measured by time in therapeutic range," Circulation, vol. 118, no. 20, pp. 2029-2037, 2008.

[62] C. Van Walraven, A. Jennings, N. Oake, D. Fergusson, and A. J. Forster, "Effect of study setting on anticoagulation control: a systematic review and metaregression," Chest, vol. 129, no. 5, pp. 1155-1166, 2006.

[63] D. E. Singer, A. S. Hellkamp, J. P. Piccini et al., "Impact of global geographic region on time in therapeutic range on warfarin anticoagulant therapy: data from the rocket AF clinical trial," Journal of the American Heart Association, vol. 2, no. 1, Article ID e000067, 2013.

[64] M. L. Flaherty, "Anticoagulant-associated intracerebral hemorrhage," Seminars in Neurology, vol. 30, no. 5, pp. 565-572, 2010.
[65] J. Fletcher, "Subgroup analyses: how to avoid being misled," British Medical Journal, vol. 335, no. 7610, pp. 96-97, 2007.

[66] X. Sun, M. Briel, S. D. Walter, and G. H. Guyatt, "Is a subgroup effect believable? Updating criteria to evaluate the credibility of subgroup analyses," British Medical Journal, vol. 340, Article ID c117, 2010.

[67] S. L. Charland, D. C. Malone, B. C. Agatep et al., "Realworld risk of thromboembolism or bleeding with warfarin or dabigatran therapy in patients with atrial fibrillation, Presentation at the American Heart Association (AHA) Scientific Sessions 2012, Los Angeles, Calif, USA, November 3-7, 2012: abstract 16370," http://www.abstractsonline.com/plan/ViewAbstract. aspx? $\mathrm{mID}=2974 \& \mathrm{sKey}=\mathrm{a} 0 \mathrm{bb} 3-\mathrm{efd}-\mathrm{f070}-4 \mathrm{c} 37-81 \mathrm{c3}$ 0ee0ede4c5a4\&cKey=b91dba5f-391f- $=4 \mathrm{f} 6 \mathrm{ca} 86 \mathrm{~d}-\mathrm{bc17b} 62 \mathrm{~b} 3299$ - \&mKey=14145D5B-F96B-4354-8237- 8F0937744BA4.

[68] T. Gomes, M. M. Mamdani, A. M. Holbrook et al., "Rates of hemorrhage during warfarin therapy for atrial fibrillation," Canadian Medical Association Journal, vol. 185, no. 2, pp. E121E127, 2013.

[69] T. A. Simon, H. Y. Huang, H. Kawabata et al., "How well do the 56, 183 atrial fibrillation patients enrolled in the contemporary novel oral anticoagulant (NOAC) trials reflect the real world?" American Public Health Association (APHA) 140th Annual Meeting \& Expo, San Francisco, CA, October 23-31, 2012: paper 270987, https://apha.confex.com/apha/ 140am/webprogram/Paper270987.html.

[70] Committee for Medicinal Products for Human Use (CHMP), Pradaxa (dabigatran etexilate) European Public Assessment Report (EPAR). Procedure No.: EMEA/H/C/000829/II/0031, 23 August, 2012, http://www.ema.europa.eu/docs/en_GB/document_library/EPAR_-_Assessment_Report_-_Variation/human/ 000829/WC500131783.pdf.

[71] S. Y. Han, S. T. Palmeri, S. H. Broderick et al., "Quality of anticoagulation with warfarin in patients with nonvalvular atrial fibrillation in the community setting," Journal of Electrocardiology, vol. 46, no. 1, pp. 45-50, 2013.

[72] H. G. Van Spall, L. Wallentin, S. Yusuf et al., "Variation in warfarin dose adjustment practice is responsible for differences in the quality of anticoagulation control between centers and countries: an analysis of patients receiving warfarin in the RELY trial," Circulation, vol. 126, no. 19, pp. 2309-2316, 2012.

[73] C. Heneghan, A. Ward, and R. Perera, "Self-monitoring of oral anticoagulation: systematic review and meta-analysis of individual patient data," The Lancet, vol. 379, no. 9813, pp. 322334, 2012. 


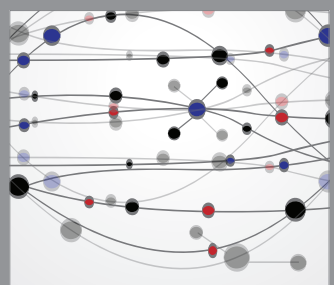

The Scientific World Journal
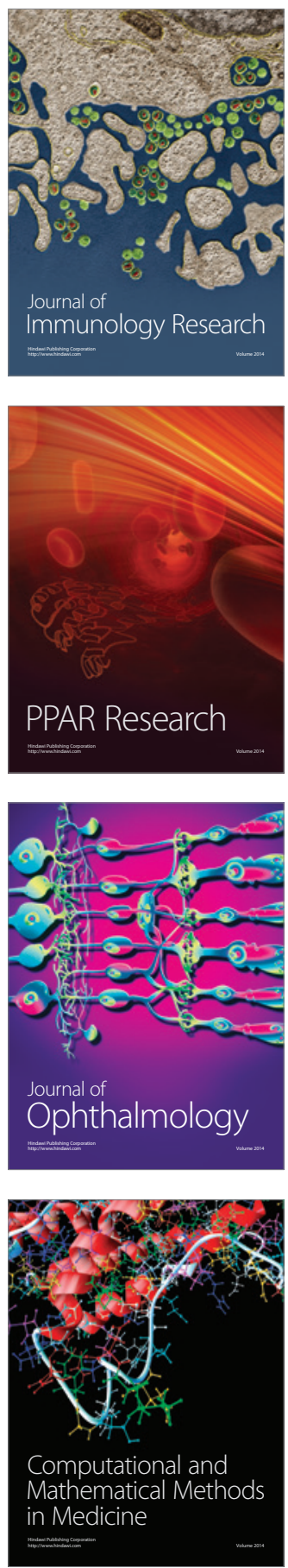

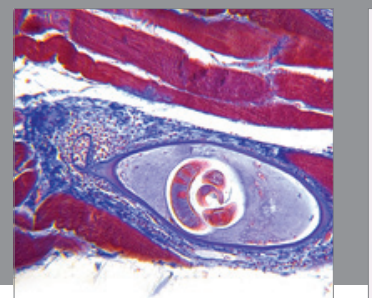

Gastroenterology

Research and Practice
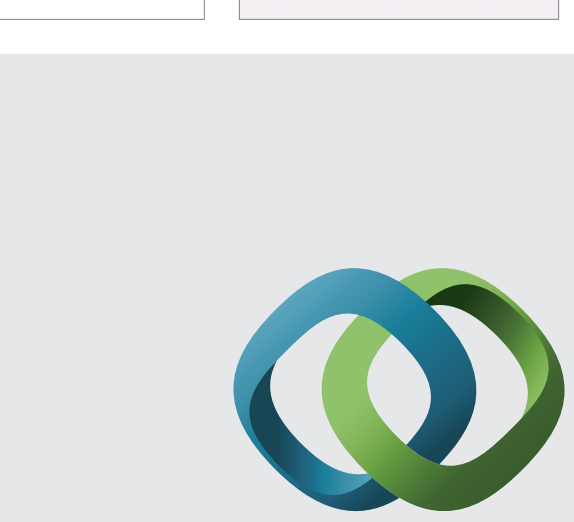

\section{Hindawi}

Submit your manuscripts at

http://www.hindawi.com
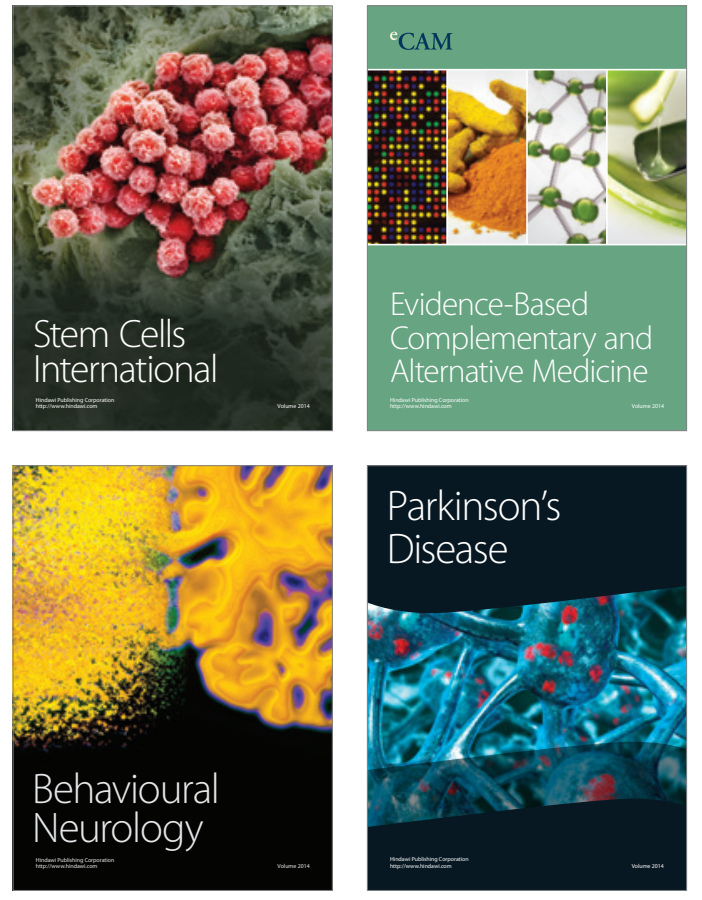
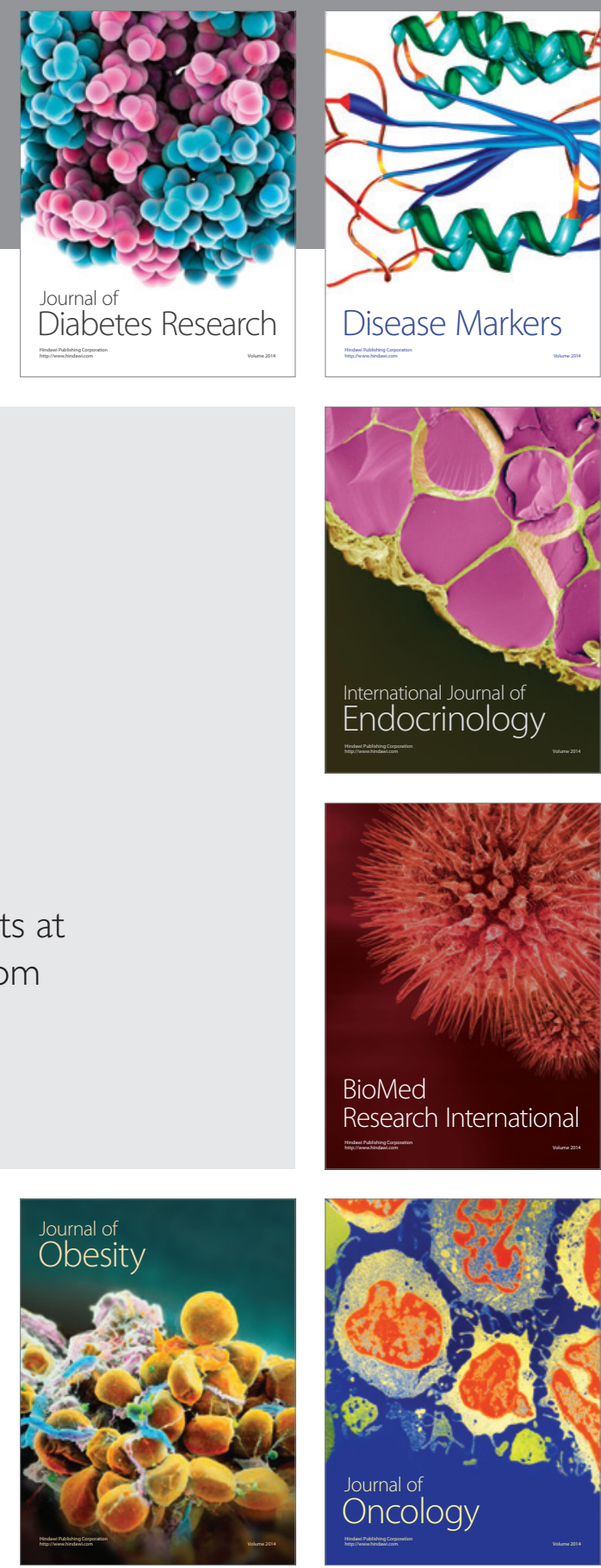

Disease Markers
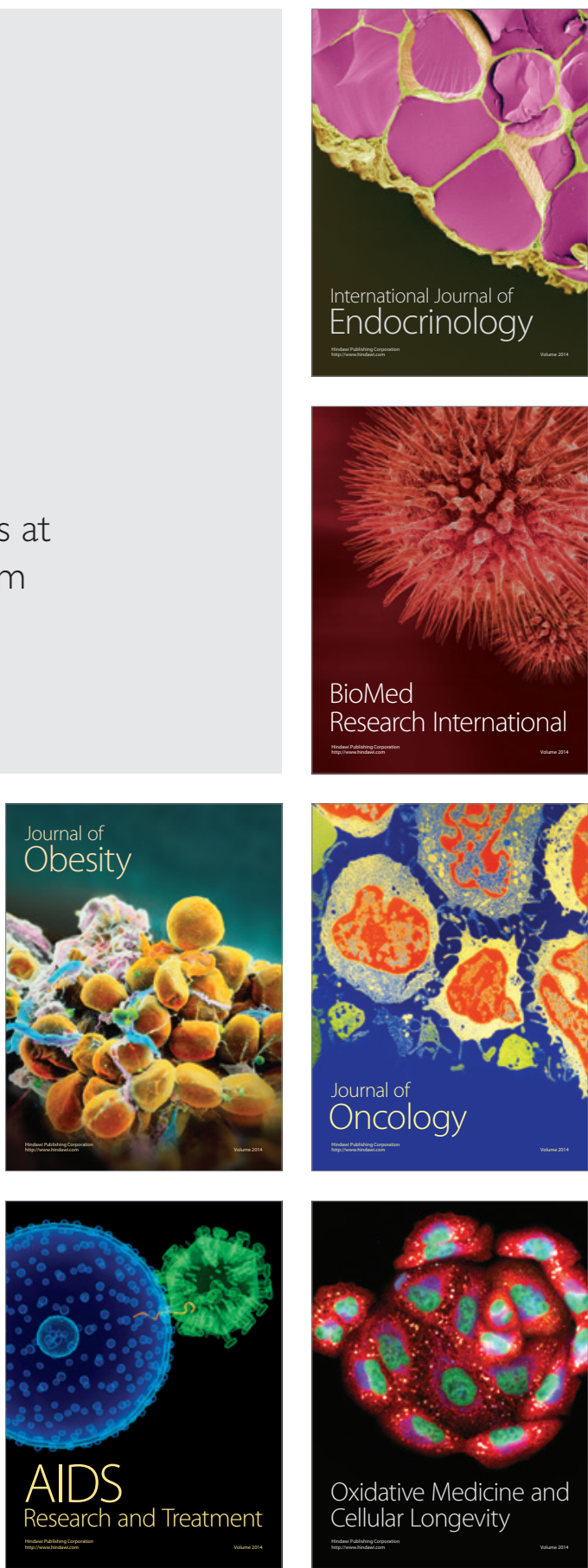